\begin{abstract}
Universidade de São Paulo - USP
Escola de Engenharia de São Carlos - EESC

Departamento de Engenharia Elétrica - SEL
\end{abstract}

Leandro Lima

\title{
Termo Eletretos de Teflon FEP como Transdutores Piezelétricos
}

São Carlos, junho de 2006 


\title{
Leandro Lima
}

\section{Termo Eletretos de Teflon FEP como \\ Transdutores Piezelétricos}

\begin{abstract}
Dissertação apresentada à Escola de Engenharia de São Carlos da Universidade de São Paulo, para obtenção do título de Mestre em Engenharia Elétrica.
\end{abstract}

Orientador: Prof. Tit. Dr. Ruy Alberto Corrêa Altafim

São Carlos, junho de 2006 


\section{DEDICATÓRIA}

Aos meus pais Marli e Cidmiro Lima por tanto amor, carinho e dedicação para a minha formação. Ao meu irmão Daniel, pelo seu amor e apoio em todas as situações. 


\section{AGRADECIMENTOS}

Ao Prof. Dr. Ruy Alberto Corrêa Altafim, que em todos os momentos orientou, contribuiu e incentivou significativamente para meu crescimento científico, sem o qual esse trabalho não teria êxito.

Ao prezado colega e amigo Ruy Alberto Pisani Altafim, pelas suas contribuições sempre pertinentes e enriquecedoras durante as discussões traçadas no desenvolvimento desse trabalho.

A todos os integrantes do Grupo de Alta Tensão do departamento de Engenharia Elétrica da Escola de Engenharia de São Carlos - GAT/SEL/EESC/USP, que contribuíram sobremaneira com as idéias e sugestões a respeito desse trabalho.

Ao Departamento de Engenharia Elétrica da Escola de Engenharia de São Carlos SEL/EESC, pela oportunidade de realização deste trabalho em suas dependências.

À Capes, pelo financiamento deste trabalho através da bolsa de pesquisa, sem a qual o sustento desse trabalho estaria limitado.

A minha querida namorada, amiga e companheira, Júlia, pelo carinho e compreensão nos momentos que estivemos separados, para que essa pesquisa pudesse se concretizar. A minha "segunda família", Carmem e Douglas Montefeltro, que me acompanham e apóiam nos mais difíceis momentos.

Agradeço também, aos demais amigos que participaram, direta ou indiretamente, deixando um pedaço de si na contribuição dessa jornada, principalmente, a Marcia Pereira Janeiro e a FURNAS CENTRAIS ELÉTRICAS que me apoiaram na finalização desse trabalho. 


\section{RESUMO}

LIMA, L. (2006). Termo Eletretos de Teflon FEP como Transdutores Piezelétricos. Dissertação (mestrado) - Escola de Engenharia de São Carlos, Universidade de São Paulo, São Carlos, 2006.

Os termo eletretos piezelétricos de Teflon FEP apresentam-se como elementos que podem competir em preço e funcionalidade com os transdutores atuais. Quando carregados impulsivamente, as folhas de Teflon FEP retêm cargas elétricas superficiais por um período longo, superior a 500 anos. Excitados mecanicamente, resultam em um alto nível de sinal elétrico e, excitados eletricamente, retornam a energia em deformação mecânica. O processo de fabricação projetado envolve a produção de um transdutor piezelétrico com uma densidade superficial de carga uniforme, através da formação de vacúolos gasosos formados sobre a superfície do filme polimérico. Os altos índices piezelétricos dos transdutores fabricados são confirmados por um sistema de medição estático, também projetado e desenvolvido neste trabalho, onde o coeficiente piezelétrico é medido de maneira direta.

Palavras chaves: Termo eletreto, Transdutor Piezelétrico, Piezeletricidade, Teflon FEP, Coeficiente piezelétrico. 


\begin{abstract}
LIMA, L. (2006). Thermo Electrets of Teflon FEP as Piezoelectric Transducers. Msc. Dissertatiton - Escola de Engenharia de São Carlos, Universidade de São Paulo, São Carlos, 2006.

The thermo-formed electrets of Teflon FEP films are shown as elements that can be competitive either in price and functionality matters, as per the transducers being used nowadays. Once charged by an impulse voltage, the Teflon FEP sheets keep the superficial electric charges for long periods, up to 500 years. Mechanically excited, they result in a high electric signal and, once electrically excited, return in a mechanical deformation. The projected manufactory process includes the production of a piezoelectric transducers with uniformly charged superficial density, through the formation of gaseous vacuoles over the polymeric film surface. The high piezoelectric levels of the manufactured transducers are confirmed by a static measurement system, also projected and developed in this same work, where the piezoelectric coefficient is measured by a direct way.
\end{abstract}

Keywords: Thermo electret, Piezoelectric Transducer, Piezoelectricity, Teflon FEP, Piezoelectric coefficient. 


\section{LISTA DE FIGURAS}

Figura 1 - Esquemático de um eletreto metalizado com cargas superficiais depositadas, cargas espaciais injetadas e cargas dipolares alinhadas (extraído de Sessler, 1998)..... .8

Figura 2 - Esquema de um sistema de carregamento por efeito corona, onde a tensão de grade controla o nível de tensão de carregamento na amostra.

Figura 3 - Esquema de ligação do sistema de carregamento por efeito impulsivo projetado por Altafim (1998), onde $\mathrm{R} 1=72 \Omega, \mathrm{R} 2=44 \Omega, \mathrm{C} 1=$ $1,35 \mathrm{mF}$ e C2 $=11 \mathrm{nF}$.

Figura 4 - Forma de onda de um carregamento impulsivo, com 1,2 $\mu$ s de frente de onda e $45 \mu$ s de tempo de meia onda. 16

Figura 5 - Esquema de uma amostra sensorial de dupla camada. 23

Figura 6 - Sistema de medição para coeficientes piezelétricos estáticos. 27

Figura 7 - Esquema de um sensor piezelétrico multicamadas de Teflon FEP com eletrodos de alumínio e vacúolos gasosos de verniz.

Figura 8 - Amostra sensorial de Teflon FEP fabricada no laboratório da Escola de Engenharia de São Carlos - EESC/USP, segundo o esquema da figura anterior

Figura 9 - Resposta elétrica de um transdutor piezelétrico multicamadas de Teflon FEP fabricado na EESC/USP. 32

Figura 10 - Resposta piezelétrica de amostras de Teflon FEP carregadas com diferentes níveis de tensão elétrica negativa.

Figura 11 -Transdutor piezelétrico com detalhes para as bolhas de verniz deterioradas 35

Figura 12 - Transdutores piezelétricos com detalhes para o fácil descolamento dos filmes poliméricos e dos eletrodos. 
Figura 13 - Transdutores piezelétricos de Teflon FEP; (a) sem metalização; (b) com metalização a ouro de 10 nm.

Figura 14 - Imagem de corte transversal feito em um filme celular PP de $70 \mu \mathrm{m}$ em duas posições (centro e inferior) feita com um microscópio SEM.

Figura 15 - Transdutor piezelétrico de Teflon FEP com detalhe para a não uniformidade do verniz aspergido e o fácil descolamento.

Figura 16 - Protótipo desenvolvido a partir de um espremedor de batatas com um sistema de aquisição de imagens, um sensor de temperatura e o sistema de vácuo.

Figura 17 - Amostras sensoriais produzidas pelo primeiro protótipo; escala de $400 \mu \mathrm{m}$.

Figura 18 - Amostras sensoriais produzidas pelo primeiro protótipo; escala de $200 \mu \mathrm{m}$ 48

Figura 19 - Diagrama Esquemático do segundo protótipo, com detalhe para o sistema de vácuo e controle de temperatura independente para os eletrodos.

Figura 20 - Segundo projeto desenvolvido no Laboratório de Medidas e Padrões da EESC/USP. .51

Figura 21 - Sistema mecânico para determinação da resposta ao impulso.....54

Figura 22 - Eletretos termo formados com várias deformidades. 56

Figura 23 -Amostra sensorial com bolhas superficiais distribuídas uniformemente. .57

Figura 24 - Resposta piezelétrica do transdutor piezelétrico de Teflon FEP com bolhas superficiais distribuídas uniformemente. 58

Figura 25 - Resposta piezelétrica do transdutor piezelétrico de Teflon FEP com bolhas superficiais distribuídas uniformemente. 58 


\section{LISTA DE TABELAS}

Tabela I. Exemplos de materiais com atividades piezelétricas.

Tabela II. Materiais poliméricos.

Tabela III. Processos de fixação do eletrodo nos transdutores piezelétricos de Teflon FEP. 


\section{LISTA DE SÍMBOLOS E ABREVIATURAS}

\begin{tabular}{|c|c|}
\hline USP & Universidade de São Paulo \\
\hline EESC & Escola de Engenharia de São Carlos \\
\hline GATM & Grupo de Alta Tensão e Medidas \\
\hline Teflon FEP & Teflon Flúor Etileno Propileno \\
\hline PVDF & Poli Fluoreto de Vinilideno \\
\hline PE & Polietileno \\
\hline Teflon PTFE & Teflon Poli Tetra Flúor Etileno \\
\hline Teflon PFA & Teflon Per Flúor Alcóxi \\
\hline Teflon AF & Teflon amorfo \\
\hline PZT & Pós de titanato zirconato de chumbo \\
\hline NASA & National Aeronautics and Space Administration \\
\hline$\vec{D}$ & Vetor deslocamento \\
\hline$\vec{E}$ & Vetor campo elétrico \\
\hline$\vec{P}$ & Vetor polarização \\
\hline$\varepsilon_{0}$ & Permissividade do vácuo \\
\hline$\varepsilon$ & Permissividade relativa do material \\
\hline$\varepsilon_{\infty}$ & Constante dielétrica para altas freqüências \\
\hline$\mu_{0}$ & Momento dipolar no vácuo \\
\hline$n$ & Número de dipolos \\
\hline$V$ & Volume \\
\hline$d_{33}$ & Coeficiente piezelétrico \\
\hline$\Omega$ & Ohm \\
\hline $\mathrm{m}$ & Mili $\left(10^{-3}\right)$ \\
\hline
\end{tabular}




$\begin{array}{cc}\mu & \text { Micro }\left(10^{-6}\right) \\ \eta & \text { Nano }\left(10^{-9}\right) \\ \rho & \text { Pico }\left(10^{-12}\right) \\ \alpha_{i} & \text { Constante de Towsend } \\ \mathrm{eV} & \text { Elétron-Volt } \\ \mathrm{N} & \text { Newton } \\ \mathrm{C} & \text { Coulomb } \\ \mathrm{F} & \text { Farad } \\ \sigma_{i} & \text { Densidade superficial de cargas } \\ \mathrm{S}_{\mathrm{ii}} & \text { Espessura de camadas } \\ \mathrm{Y} & \text { Módulo de Yang } \\ \Delta p & \text { Força aplicada no filme polimérico } \\ \mathrm{V} & \text { Tensão elétrica } \\ \mathrm{F} & \text { Força mecânica (N) }\end{array}$




\section{SUMÁRIO}

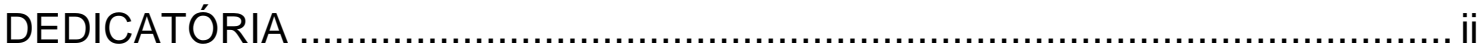

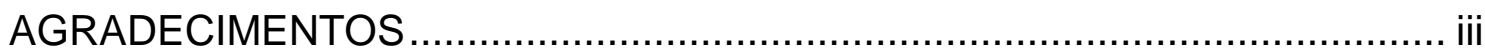

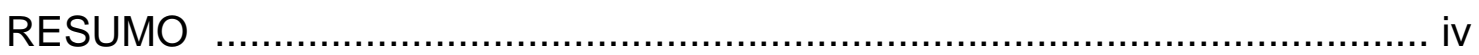

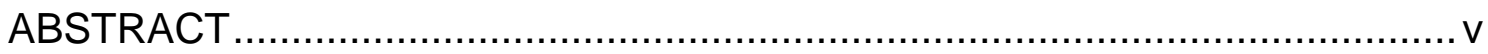

LISTA DE FIGURAS …................................................................... vi

LISTA DE TABELAS ...........................................................................iii

LISTA DE SÍMBOLOS E ABREVIATURAS ……....................................... ix

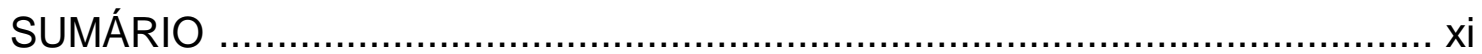

1 - Introdução

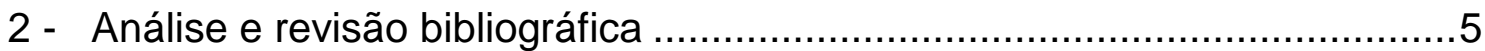

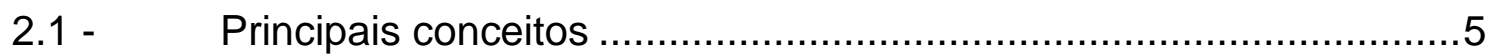

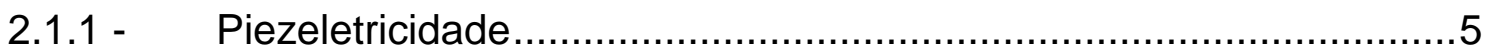

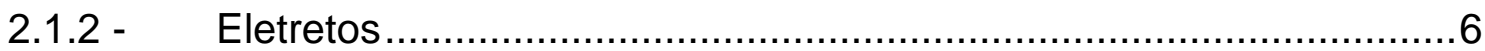

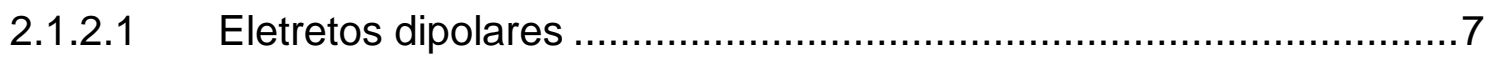

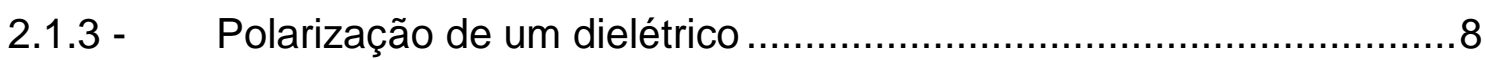

2.2 - Estado da arte da piezeletricidade .................................................10

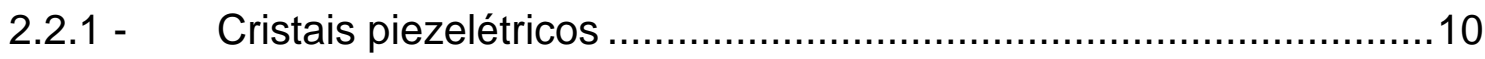

2.2.2 - Filmes poliméricos …..........................................................13

2.3 - Sistemas de carregamento para filmes poliméricos........................14

2.3.1 - Carregamento por efeito corona …………................................14

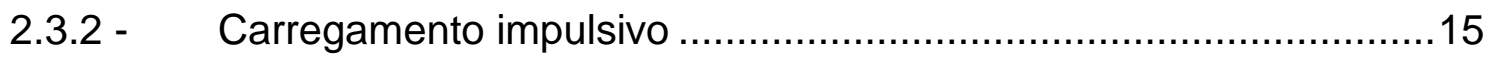

2.3.3 - Materiais comumente utilizados .................................................18

2.4 - Eletretos poliméricos de Teflon FEP ……..................................19 
2.4.1 - Campo elétrico no interior da amostra ……..............................23

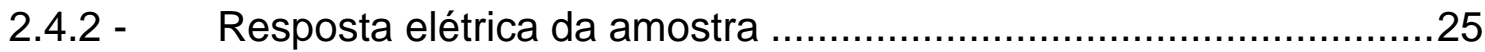

3 - Transdutores piezelétricos de Teflon FEP ............................................28

3.1 - Sensor multicamada de Teflon FEP produzido de maneira artesanal 30

3.2 - Resultados experimentais dos sensores produzidos de maneira

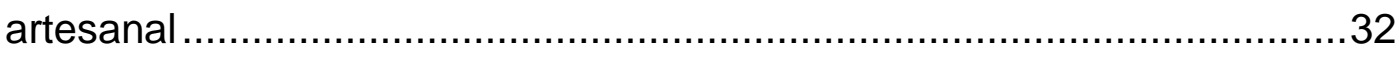

3.3 - Análise crítica do sensor existente...............................................33

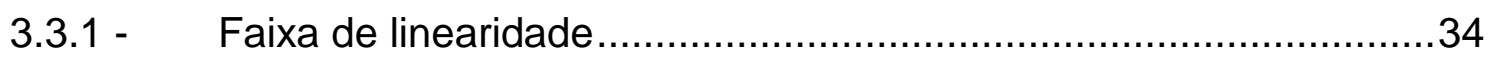

3.3.2 - Compressão dos vacúolos internos formados com verniz ...............34

3.3.3 - Destruição do sensor piezelétrico frente a um stress prolongado...35

4 - Novo sensor piezelétrico denominado termoformado...............................38

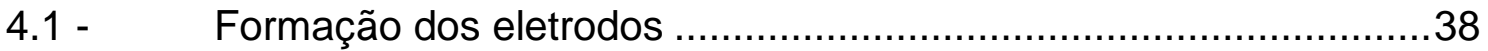

4.2 - Formação de bolhas de ar uniformes entre os filmes de teflon.......42

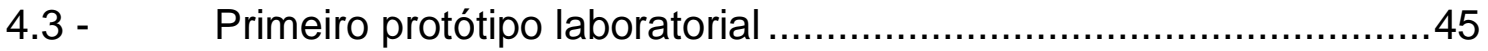

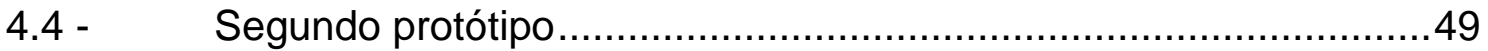

4.5 - Desenvolvimento de um sistema para medição das características estáticas dos sensores piezelétricos. ...................................................

4.5.1 - Fatores influentes na determinação da resposta do sensor.............52

4.5.2 - Resposta do sensor a um impulso mecânico..................................54

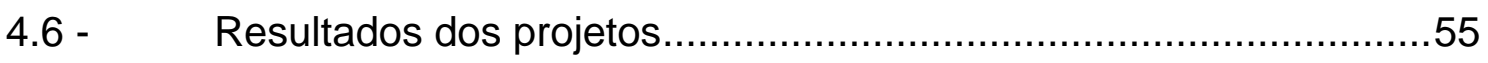

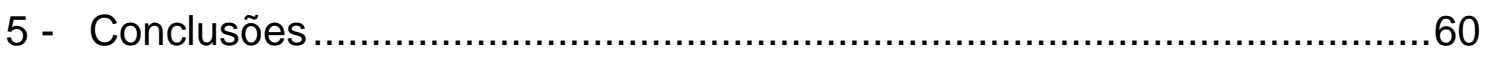

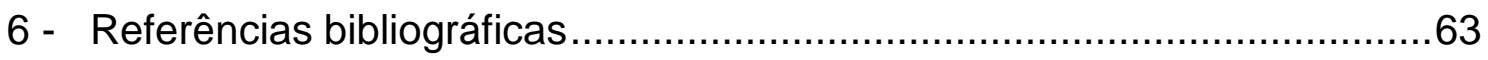

Anexo A - Características do Teflon FEP...................................................67 


\section{1 - INTRODUÇÃO}

Desde o início do século XIX, o comportamento de cargas elétricas em materiais dielétricos tem sido alvo de estudo para grandes pesquisadores, dentre eles Gray, Curie, Faraday, Heaviside e outros. Atualmente, em diversos países, esses materiais carregados eletricamente têm sido um dos principais motivos de pesquisas em diversos laboratórios de renome.

As cargas elétricas aprisionadas em um material isolante conferem-lhe características especiais, em particular, a propriedade da piezeletricidade encontrada inicialmente nos cristais e, posteriormente, descoberta em polímeros. Essas descobertas abriram portas na área da física, da química e da engenharia para novas tecnologias de sensores.

Os cristais piezelétricos são normalmente utilizados em diversas aplicações como micro-transdutores de pressão e transdutores eletroacústicos. Já os polímeros, sejam celulares, porosos ou rígidos, estão obtendo espaço na implementação de microfones, transdutores de pressão, sensores de vibração mecânica, balanças comerciais e outros dispositivos. Encontramse também presentes na área da bioengenharia, pois apresentam uma excelente relação custo-benefício, devido ao baixo custo dos polímeros. Somase a isto a vantagem de atingirem níveis de coeficientes piezelétricos muito superiores aos exibidos pelos cristais e apresentarem melhores características térmicas, mecânicas e elásticas.

O presente trabalho tem como foco principal à fabricação de transdutores piezelétricos de Teflon FEP (Flúor Etileno Propileno) com interstícios gasosos uniformes que, submetidos ao processo de carregamento impulsivo (ALTAFIM, 1992), são capazes de exibir um alto coeficiente 
piezelétrico $\left(d_{33}\right)$. A partir da composição de um sistema multicamadas, os filmes poliméricos de Teflon® FEP, de patente da DuPont, serão preparados e carregados através de um impulso de tensão, com a finalidade de serem submetidos a uma caracterização estática e dinâmica.

A importância deste trabalho se dá pela crescente utilização de transdutores piezelétricos no mercado, sendo que o emprego do material polimérico e as técnicas de carregamento conhecidas oferecem uma relação custo-benefício inferior aos dispositivos encontrados atualmente, conforme estudos econômicos de Kestelman et al. (2000, p.268-272).

Rodrigues (2003) publicou um trabalho onde descreve a forma artesanal de fabricação de amostras piezelétricas, montadas em forma de um sanduíche de dupla camada de Teflon FEP, contendo bolhas artificiais criadas por um verniz comercial. Por meio da caracterização estática dessas amostras, foi possível observar que elas apresentam coeficientes piezelétricos elevados. Entretanto, como a técnica de fabricação empregada é precária, os eletrodos de alumínio tendem a se descolar facilmente, pois são colados com o mesmo tipo de verniz. Em um ensaio mais refinado, como por exemplo, um teste dinâmico, visando à obtenção da curva de resposta em freqüência do transdutor, as folhas de Teflon FEP se separam totalmente, destruindo todo o elemento sensor.

Internamente, outro problema foi detectado: a não uniformidade das bolhas artificiais presentes no interior das amostras que ocasionam diferentes níveis de coeficientes piezelétricos. Tendo em vista essa não uniformidade dos vacúolos gasosos ("voids" em inglês), a confiabilidade do produto encontra-se comprometida, uma vez que o processo de fabricação não é repetitivo, devido à grande variação nas respostas elétricas obtidas com amostras fabricadas de maneira semelhante.

A estrutura química dos filmes poliméricos permite uma alta retenção de cargas, quando devidamente carregados. Portanto, os altos coeficientes piezelétricos já confirmados por Hillenbrand (2004), Multhaupt (2002a), Sessler (2001) e outros servem de base para este trabalho, no que tange ao desenvolvimento de melhores amostras de Teflon FEP. A escolha do teflon, composto de Flúor-Etileno-Propileno, se deve por sua estrutura microscópica 
apresentar armadilhas superficiais rasas e profundas capazes de reter cargas elétricas negativas com facilidade.

Para que o sensor possa atender às necessidades de mercado, com vistas a uma produção em larga escala, é necessária sua caracterização estática e dinâmica, a fim de verificar a faixa de resposta em freqüência do transdutor piezelétrico.

Todo o processo de fabricação e produção será definido e projetado, passando de um sistema totalmente artesanal a um protótipo industrial, visando a uma produção em larga escala, minimizando-se os problemas encontrados por Rodrigues (2003), como mau contato e descolamento dos eletrodos, separação das folhas do polímero frente ao stress mecânico, falta de uniformidade na distribuição dos vacúolos gasosos na superfície do material, perda de carga devido à condutividade das bolhas, etc.

Este trabalho também visa ao desenvolvimento de um instrumento de impacto para caracterização estática das amostras sensoriais fabricadas. A caracterização dinâmica é alvo de um estudo de mestrado desenvolvido paralelamente por Ruy Alberto Pisani Altafim, visando a uma maior confiabilidade nos resultados, validando o processo de fabricação aqui sugerido, dentro de uma faixa de freqüência pré-estabelecida. As respostas serão obtidas através de dois métodos conhecidos: obtenção do coeficiente piezelétrico de maneira direta e inversa, confirmando, assim, as descobertas de Curie publicadas em 1881, onde ele afirma que tais coeficientes são iguais (BALLATO, 1995, 1996; BROW et al., 1962).

O termo sensor de Teflon FEP é uma tecnologia inovadora e foi integralmente desenvolvido pelo Grupo de Alta Tensão e Medidas (GATM), da Escola de Engenharia de São Carlos - Universidade de São Paulo (EESC/USP), sob a orientação de o Professor Titular Dr. Ruy Alberto Corrêa Altafim, cujas pesquisas de doutorado precedem as idéias desse trabalho, bem como o processo de carregamento impulsivo utilizado.

Para uma melhor organização, o estudo foi dividido em capítulos, tais como explanados a seguir: 
No capítulo 2 serão explorados os principais conceitos teóricos (piezeletricidade, polarização de dielétricos, eletretos e outros) referentes ao embasamento desta pesquisa, bem como o estado da arte em toda a sua extensão, isto é, o desenvolvimento e os estudos realizados, desde as primeiras descobertas até as publicações mais recentes, no intuito de se correlacionar este trabalho no âmbito nacional e internacional. Também será abordada uma visão dos diversos tipos de carregamento de eletretos, juntamente com todo o processo evolutivo ao longo das décadas, a fim de se justificar o carregamento impulsivo empregado nas amostras sensoriais, frente aos níveis de respostas e deposição de cargas elétricas, tendo em vista a melhor relação custo-benefício.

Os transdutores piezelétricos fabricados atualmente serão estudados e criticados no capítulo 3 , no intuito de elaborar-se uma análise apurada em toda a sua estrutura de fabricação, a fim de melhorar os pontos fracos e propor modificações significantes no processo.

No capítulo 4, será apresentado todo o processo de análise e implementação da fabricação do novo sensor piezelétrico denominado termoformado, bem como as novas técnicas desenvolvidas no GATM para a correção dos problemas encontrados na fabricação artesanal. Também será descrita as dificuldades e obstáculos surgidos no decorrer desse projeto.

Os principais resultados dos novos sensores fabricados serão demonstrados e comentados também no capítulo 4.

O capítulo 5 finalizará os estudos desenvolvidos, correlacionando-se as conclusões encontradas no decorrer desse trabalho, assim como, as várias portas de pesquisa que esse trabalho abre.

As referências bibliográficas serão organizadas em ordem alfabética no capítulo 6, para que o leitor tenha um fácil acesso a qualquer fonte mencionada durante o desenvolvimento deste trabalho.

O anexo A contém todas as informações técnicas da Dupont sobre o filme polimérico de flúor carbono, Teflon® FEP, empregado na fabricação dos termos eletretos (transdutores piezelétricos). 


\section{2 - ANÁLISE E REVISÃO BIBLIOGRÁFICA}

O estado da arte será suporte para estruturação deste trabalho, visto que abordará conceitos importantes, para o entendimento do efeito piezelétrico, da formação dos eletretos e das principais descobertas e inovações na área de cristais e filmes poliméricos.

Juntamente com os conceitos acima descritos, também será abordada resumidamente a evolução da piezeletricidade em polímeros até os dias atuais, procurando traçar o panorama que motivou este trabalho.

\section{1 - Principais conceitos}

O campo dos materiais piezelétricos é muito vasto. Antes de uma abordagem cronológica dos principais descobrimentos faz-se necessária a explanação de três conceitos importantes, a saber, a piezeletricidade, a polarização de dielétricos e os eletretos, que embora suas pesquisas iniciem-se praticamente em separado, eles fundem-se na área deste trabalho.

\subsection{1 - Piezeletricidade}

O termo piezeletricidade refere-se à propriedade exclusiva que alguns materiais altamente isolantes apresentam, resultando um sinal de tensão elétrica provocada por uma deformação mecânica, isto é, quando da aplicação de uma pressão com direção e orientação definidas sobre o material, um sinal 
elétrico é gerado devido à movimentação de cargas internas existentes nos materiais.

Dentre os materiais dielétricos, destacam-se alguns polímeros, tais como o Poli Fluoreto de Vinilideno (PVDF), o Polietileno (PE), e os polímeros fluorados como o Teflon Flúor Etileno Propileno (Teflon FEP), o Teflon Poli Tetra Flúor Etileno (Teflon PTFE), o Teflon Per Flúor Alcóxi (Teflon PFA) e outros.

O dicionário de termos técnicos da National Aeronautics and Space Administration (NASA) define piezeletricidade como sendo "a propriedade exibida por alguns materiais cristalinos assimétricos quando estão sujeitos a uma deformação mecânica, em direção apropriada, exibindo uma polarização elétrica proporcional à pressão".

Entretanto, Gerhard-Multhaupt (2002b) simplifica, afirmando que a piezeletricidade é um fenômeno estritamente linear, que relaciona qualquer deslocamento mecânico e tensão elétrica, ou qualquer tensão elétrica e deslocamento mecânico como causa e efeito, respectivamente.

Atualmente, o efeito piezelétrico é o responsável pelo princípio de funcionamento de vários equipamentos eletro-acústicos, desde a invenção do primeiro microfone de eletreto, advinda dos estudos realizados por Gross em 1944, até os mais modernos sistemas de transdutores acústicos de pressão.

\subsection{2 - Eletretos}

O termo eletreto foi empregado pela primeira vez em 1885 por Oliver Heaviside, para designar dielétricos com dipolos orientados que apresentavam um campo elétrico residual. Entretanto, atualmente este termo também designa materiais que têm a propriedade de reter cargas elétricas por longos períodos, como os eletretos compostos por deposição de cargas (GERHARDMULTHAUPT, 2002b).

Materiais amorfos, policristalinos e substâncias parcialmente cristalinas são exemplos bem sucedidos de substâncias onde as cargas elétricas podem 
ser aprisionadas em armadilhas, em razão principalmente da estrutura molecular anisotrópica que apresentam. O Teflon FEP, em sua estrutura microscópica não homogênea, retém cargas elétricas negativas com grande facilidade em armadilhas energéticas superficiais profundas. Estas cargas elétricas, quando aprisionadas, permanecem estáveis, presas à estrutura molecular do teflon por um longo período de tempo superiores a 500 anos (GERHARD-MULTHAUPT, 1999, p.1-40).

\subsubsection{Eletretos dipolares}

Todo material é constituído por um conjunto de átomos e, portanto, apresentam cargas elétricas em sua composição. Em materiais dipolares, estas cargas possuem um certo grau de liberdade, dependente diretamente das características intrínsecas do material, principalmente da temperatura e da viscosidade e, na presença de um agente externo, estas cargas podem sofrer movimentação (orientação), segundo uma determinada aplicação.

Quando esse material apresentar uma resultante de cargas nula, isto é, macroscopicamente a somatória das forças internas é igual à zero, não existirá um momento de dipolo e pode-se dizer que o material encontra-se em equilíbrio. Porém, com a presença de um campo elétrico externo, os dipolos elétricos podem orientar-se de maneira tal, que o material exibirá as características de um corpo carregado eletricamente.

Com a retirada deste campo elétrico, os dipolos tendem a retornar à posição inicial. Entretanto, em alguns corpos altamente isolantes, esse efeito pode permanecer indefinidamente. A taxa de orientação das cargas elétricas nos materiais depende da mobilidade que os dipolos apresentam. Esta pode ser tão pequena que os materiais continuam a exibir tais características por séculos, formando então, os eletretos. 


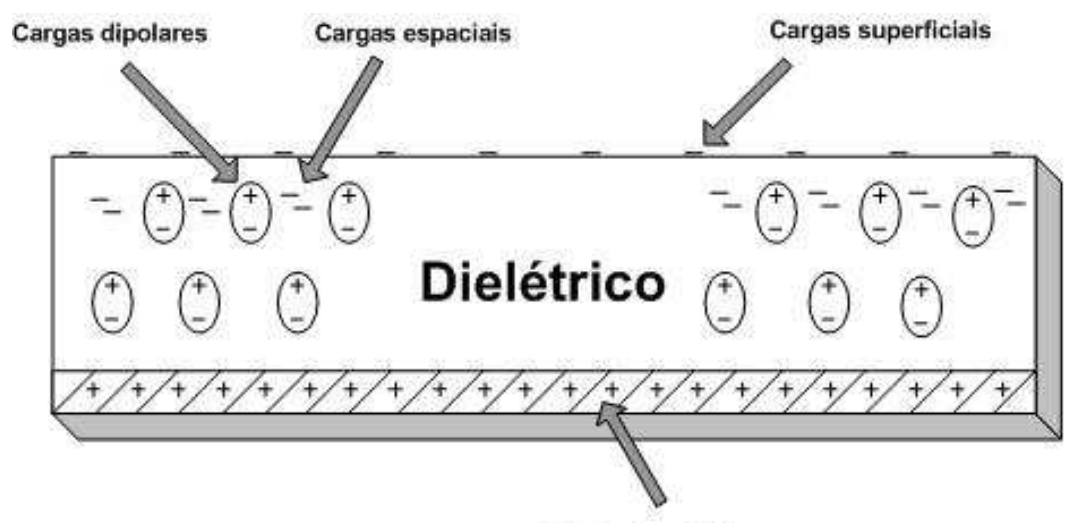

Eletrodo metálico

Figura 1 - Esquemático de um eletreto metalizado com cargas superficiais depositadas, cargas espaciais injetadas e cargas dipolares alinhadas (extraído de Sessler, 1998).

A influência da temperatura na maleabilidade e orientação dos dipolos em um corpo foi estudada por Gross e Denard, nos anos de 1944 e 1945. O aumento da temperatura sobre um corpo com cargas dipolares facilita a orientação dos dipolos no interior do corpo, quando sobre a ação de um gradiente de potencial externo, inferindo portanto, que nestas condições, um nível menor de tensão seja necessário para se obter um mesmo resultado. De maneira análoga, ao se resfriar o material aquecido na presença deste campo elétrico, os dipolos permanecerão orientados. A temperatura portanto, é um ente que age diretamente sobre a maleabilidade dos dipolos no material estudado.

\subsection{3 - Polarização de um dielétrico}

Um dielétrico pode ser polarizado na presença de um gradiente de potencial externo. Maxwell equacionou que o campo elétrico é proporcional ao deslocamento $\vec{D}$ das cargas elétricas em um dielétrico, segundo a equação abaixo,

$$
\vec{D}=\varepsilon \vec{E}
$$


onde $\varepsilon$ representa a permissividade relativa do material.

O modelo matemático para se descrever o efeito piezelétrico exibido em um dielétrico pode ser estabelecido segundo um capacitor de placas planas paralelas. Surge então, a polarização do dielétrico, completando as premissas de Maxwell, o vetor polarização $\vec{P}$.

$$
\vec{D}=\varepsilon_{0} \vec{E}+\vec{P}
$$

Este vetor é característica intrínseca de cada dielétrico, segundo descrito por Wang (1988), sendo equacionado por:

$$
\vec{P}=\frac{\left(\varepsilon_{\infty}+2\right) n \mu_{0}}{3 V} \cos (\theta)
$$

onde $\varepsilon_{\infty}$ representa a constante dielétrica para altas freqüências, $\mu_{0}$ é o momento dipolar no vácuo e $n$ é o número de dipolos no volume $V$.

Como o vetor polarização possui direção e sentido definidos pela orientação das cargas elétricas, qualquer deformação na estrutura do material piezelétrico altera a resultante elétrica total no material.

De uma forma geral, a piezeletricidade ocorre mediante uma dependência linear estabelecida entre uma tensão ou corrente elétrica, induzida nos eletrodos e, uma correspondente solicitação ou deformação mecânica que é aplicada no sistema, ou senão, de modo recíproco.

A piezeletricidade é um termo que se encontra presente nos mais diversos tipos de materiais, de cristais a polímeros, sendo responsável por exibir uma "transformação" de energia mecânica em elétrica, e vice-versa. 


\section{2 - Estado da arte da piezeletricidade}

Descritos brevemente os conceitos e definições do efeito piezelétrico e orientação ou aprisionamento de cargas para formação de eletretos, um breve histórico será abordado, contendo os principais avanços neste campo, tendo em vista a formação de uma base sólida para o desenvolvimento dos termo sensores de Teflon FEP com bolhas uniformes.

Em 1732, Gray observou as primeiras propriedades dos eletretos em alguns materiais. Posteriormente, estudos foram desenvolvidos por Faraday e Heaviside. Em 1919, Eguchi desenvolve pesquisas com a cera de carnaúba. Gross, em 1944/45, desenvolve importante trabalho com suas pesquisas sobre a influência da temperatura nestes materiais.

Estes conceitos desenvolvidos e as experiências realizadas deram início à consolidação dos princípios sobre eletretos utilizados atualmente em trabalhos no mundo todo.

Após os cristais piezelétricos, ceras e resinas, surgiu um grande interesse de trabalhos no campo dos materiais poliméricos, visto que as propriedades piezelétricas exibidas por esse tipo de material eram mais interessantes que nos cristais.

No campo polimérico, grandes nomes se destacam, como Sessler, Eichi Fukada, Gerhard-Multhaupt, e outros, acrescentando grandes contribuições na área da piezeletricidade.

\subsection{1 - Cristais piezelétricos}

Em toda a história, a data mais antiga em que se registrou conhecimentos acerca dos eletretos foi na pessoa de Gray, em 1732, quando observou a energia estática em materiais dielétricos como ceras, resinas vegetais e enxofre.

Gray verificou o aparecimento de uma certa quantidade de energia elétrica ao se atritarem materiais dielétricos, intitulando, esse fenômeno observado como uma "força atrativa perpétua". 
Somente em 1839, Michael Faraday realiza estudos, observando um estranho fenômeno em capacitores. Ao serem carregados, devido à ação de um campo elétrico externo, os capacitores continuam a apresentar certa quantidade de carga elétrica residual mesmo após a retirada desse campo, e, conseqüente, curto-circuito momentâneo em seus terminais.

O efeito de uma carga elétrica residual observada em um material dielétrico foi atribuído a uma movimentação de elétrons dos eletrodos para o meio dielétrico, denotando portanto, que um dielétrico é capaz de reter cargas elétricas mesmo após a presença do campo aplicado.

A piezeletricidade nasceu do interesse científico dos irmãos Curie, seguido dos trabalhos de Coulomb nas décadas de 1780 e 1790, onde foi observado o aparecimento de cargas elétricas pela simples compressão de materiais cristalinos.

Em 1881, Lippmann encontra o efeito inverso da piezeletricidade aplicando cargas elétricas na superfície dos materiais e obtendo, como resultado, uma deformação mecânica. Curie, analisando tais resultados, verifica que os coeficientes piezelétricos direto e inverso são iguais.

Em paralelo, surgem as pesquisas com eletretos (termo eletretos), como mencionado anteriormente, praticamente estabelecido por Oliver Heaviside, traduzindo uma analogia aos magnetos ou ímãs permanentes conhecidos na época, a fim de justificar o fato dos dielétricos polares exibirem um campo elétrico residual.

A partir de 1919, sistemáticas pesquisas no campo dos eletretos começaram a se desenvolver com o físico japonês Mototaro Eguchi. Com resinas vegetais, cera de carnaúba e cera de abelha, Eguchi formou eletretos através do processo térmico desenvolvido por Gray.

Nesse processo, o material aquecido foi submetido a um campo elétrico externo. Devido à alta temperatura, as cargas elétricas se orientavam paralelamente ao campo. O material então, na presença desse campo, era resfriado lentamente, retirando-se a maleabilidade que os dipolos possuíam advinda da temperatura elevada. 
Sendo assim, o material resfriado e sem a atuação do campo externo exibia um magnetismo residual por longos anos, formando portanto, um eletreto (HILCZER, 1986, p.1-6).

Eguchi também observou que o material polarizado apresentava cargas elétricas de polaridades opostas às aplicadas pela fonte externa. Entretanto, no decorrer de alguns dias, ocorria uma inversão da polaridade das cargas presentes na superfície do material, isto é, o eletreto formado inicialmente por cargas de polaridades opostas às originadas pelos eletrodos, dava lugar às cargas de mesma polaridade do campo elétrico aplicado.

Bernard Gross e Denard, em 1944, explicam este fato denominando as cargas elétricas presentes no material de hetero e homocargas, respectivamente. Ao passo que as heterocargas "desaparecem" rapidamente, as homocargas, mais estáveis, perduram por vários anos (SESSLER, 1998, p.3).

Gross e Denard também realizam estudos complementares do comportamento das cargas elétricas frente à temperatura de preparo da amostra, relatando que esta influencia diretamente na quantidade de cargas presente no eletreto.

A principal propriedade de um eletreto é ser um armazenador de cargas e detentor de um campo elétrico que permanece por um longo período no material, mesmo sem a aplicação de um campo elétrico externo. Dois são os fenômenos que explicam a presença de um campo elétrico residual em um material dielétrico, a polarização dielétrica e o aprisionamento de cargas elétricas por armadilhas energéticas.

Diante destas pesquisas, Paul Langevin desenvolveu a primeira aplicação prática utilizando eletretos. Construindo o sonar, muito utilizado durante a época da primeira guerra mundial para localizar submarinos, Langevin passou a ser conhecido como "o pai do sonar" e da disciplina de ultra-sônica (BALLATO, 1996).

Outro desenvolvimento que revolucionou a ciência se deu em 1921, quando Cady empregou o efeito piezelétrico encontrado nos cristais de quartzo 
para a estabilização de osciladores. Isso possibilitou a Bechmann implementar tais osciladores para um efetivo controle de freqüência em circuitos eletrônicos.

Dando continuidade às pesquisas, no ano de 1928, Selenyi desenvolveu um processo de formação de eletretos através da injeção de elétrons ou íons na cera de carnaúba. Anos mais tarde, extensões desse trabalho resultaram no desenvolvimento da gravação eletrostática, onde imagens fotocondutivas eram formadas, originando assim o processo de xerografia na década de $40 \mathrm{com}$ as contribuições de Carlson.

O processo de formação de fotoeletretos se deu quando Nadjakoff, em 1938, substituiu o aquecimento do material dielétrico por um feixe incidente de luz. Posteriormente, na década de 50, estudos resultaram em processos de ionização por efeito radioativo.

Durante o desenvolvimento da xerografia, Selenyi tornou o processo de injeção de elétrons em dielétricos dependente de um processo corona, que mais tarde estendeu-se a eletretos formados por filmes poliméricos.

\subsection{2 - Filmes poliméricos}

Propriedades piezelétricas foram investigadas e encontradas em materiais biológicos e poliméricos por Fukada (2000), entre as décadas de 50 e 60.

Após essas décadas, houve uma menor evolução dos trabalhos de pesquisa nesta área, porém, em 1969, com as descobertas de um alto coeficiente piezelétrico em filmes poliméricos de PVDF, por Kawai, despertouse um grande interesse por pesquisas em eletretos formados principalmente por diversos filmes poliméricos (FUKADA, 2000).

Em concordância com a extensa vida útil de eletretos poliméricos, em 1962 foi fabricado o primeiro microfone de eletreto, fruto das pesquisas em materiais piezelétricos. Desde então, transdutores piezelétricos são utilizados em larga escala no mercado como microfones, detectores piroelétricos, sensores de presença e filtros, dentre outros. 
Durante a década de 90, o surgimento dos filmes poliméricos porosos e celulares, resultou em materiais que apresentavam altos coeficientes piezelétricos. Tais polímeros não apresentam uma estrutura molecular bipolar, mas vacúolos gasosos em sua composição, que além de diminuir a massa dos filmes poliméricos, formam grandes dipolos quando carregados eletricamente (GERHARD-MULTHAUPT, 2002b).

Conforme estes altos coeficientes piezelétricos encontrados nos mais variados filmes poliméricos, aumentou-se o interesse por pesquisas científicas nessa área. Portanto, as últimas décadas do século XIX e o início do XX têm contribuído sobremaneira para o desenvolvimento da ciência neste campo. Devido à facilidade de obtenção e baixo custo dos filmes poliméricos, bem como a exibição de efeitos piezelétricos serem muito superiores aos encontrados nos cristais, muitas aplicações têm sido supridas por finas camadas de polímeros, pois além de se adequarem perfeitamente à dimensão física da aplicação desejada, são elementos de fácil carregamento e grande estabilidade de cargas.

\section{3 - Sistemas de carregamento para filmes poliméricos}

\subsection{1 - Carregamento por efeito corona}

O método de carregamento por efeito corona bombardeia o material dielétrico a ser carregado, através de uma descarga corona no ar ou feixes eletrônicos no vácuo. Os íons são gerados pela aplicação de uma alta tensão em uma ponta metálica, situada perto de uma das faces do dielétrico. Ocorre literalmente uma "chuva" de elétrons sobre o dielétrico, como ilustra a figura abaixo, carregando-o eletricamente. 


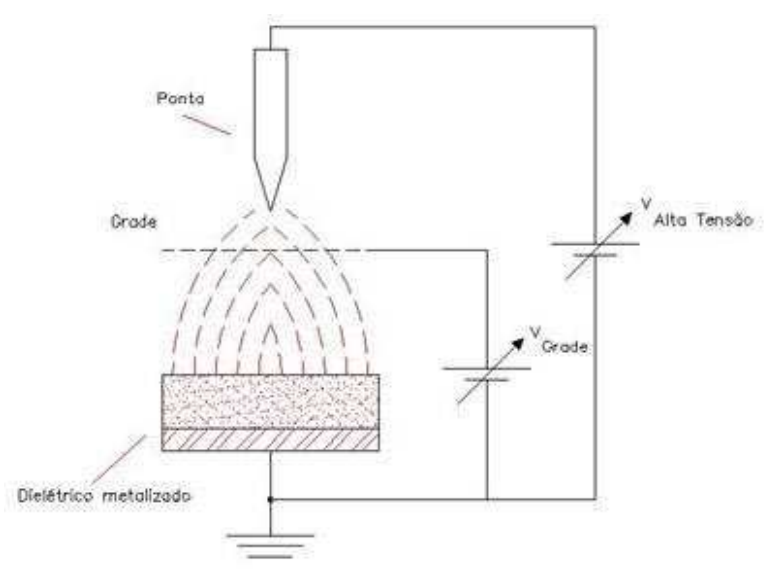

Figura 2 - Esquema de um sistema de carregamento por efeito corona, onde a tensão de grade controla o nível de tensão de carregamento na amostra.

Como o Teflon FEP tem a facilidade de reter cargas elétricas negativas em suas armadilhas superficiais, ao aplicar uma alta tensão negativa na ponta metálica, ter-se-á um efeito corona que depositará os portadores negativos na superfície do material dielétrico.

Nesse processo de carregamento, é difícil controlar a densidade de cargas elétricas depositadas na superfície do dielétrico. Para tanto, existe um controle de tensão através da grade metálica, amenizando este problema. A diferença de tensão entre a grade e a tensão aplicada na ponta metálica é diretamente proporcional à densidade de cargas que se deseja depositar na superfície do termo sensor.

Apesar do inconveniente de que os materiais a serem carregados necessitam ficar expostos a tensões elevadas por um longo período de tempo, o método de carregamento por efeito corona ainda é bastante utilizado (GERHARD-MULTHAUPT, SESSLER, GIACOMETTI e outros).

\subsection{2 - Carregamento impulsivo}

Devido ao alto tempo de exposição e custos envolvidos no processo, Altafim (1992) elaborou um método de carregamento e validou (ALTAFIM, 1998) aplicando-se uma onda de tensão impulsiva, com pico elevado, diretamente sobre o filme polimérico. Gerhard-Multhaupt (2002a) e Altafim 
(2003, 2005, 2006) utilizam este processo impulsivo com grande eficiência, para também carregar polímeros celulares e porosos e obter materiais com altos coeficientes piezelétricos.

A configuração básica do carregador por impulso e a forma de onda gerada, está demonstrado nas figuras abaixo.

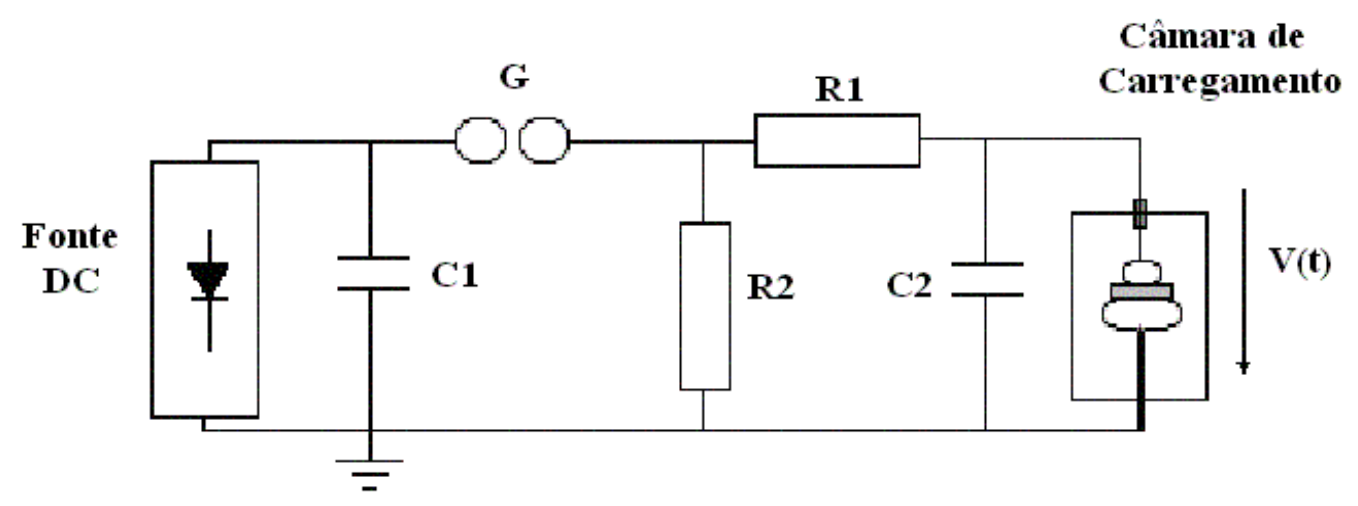

Figura 3 - Esquema de ligação do sistema de carregamento por efeito impulsivo projetado por Altafim (1998), onde $\mathrm{R}_{1}=72 \Omega, \mathrm{R}_{2}=44 \Omega, \mathrm{C}_{1}=1,35 \mathrm{mF}$ e $\mathrm{C}_{2}=11 \mathrm{nF}$.

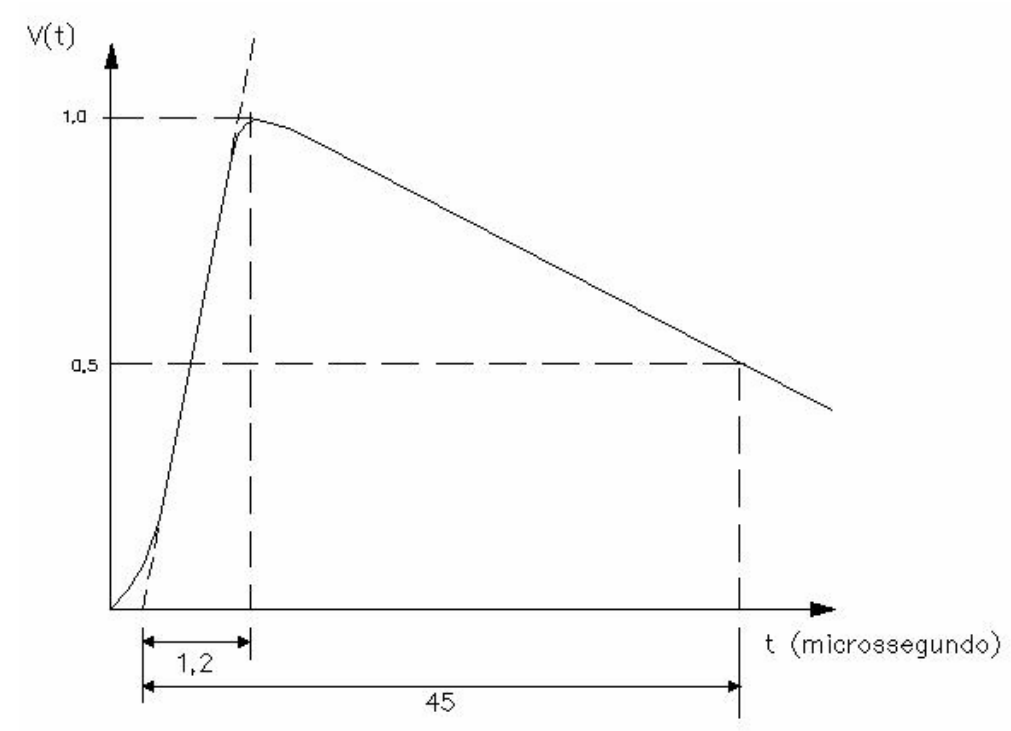

Figura 4 - Forma de onda de um carregamento impulsivo, com 1,2 $\mu$ s de frente de onda e $45 \mu$ s de tempo de meia onda. 
Um pico de tensão negativa de curta duração é aplicado sobre um filme polimérico, induzindo o aprisionamento de cargas elétricas na superfície do filme, formando termo eletretos em um curto espaço de tempo. Como pode ser observada na figura 4, uma das vantagens do carregamento impulsivo frente ao carregamento corona, é que o tempo de carregamento de um transdutor piezelétrico por impulso é da ordem de micro segundos.

Os armazenadores de carga capacitivos são carregados negativamente por uma fonte de tensão dc - modelo Spellmam, High Voltage DC Supply. Ao atingir o potencial desejado, essa energia (um pico de tensão impulsiva) é descarregada sobre a amostra, fixada dentro da câmara de carregamento.

A tensão a que o filme dielétrico é submetido é dada segundo a equação abaixo.

$$
v(t)=v_{0}\left(e^{-\alpha_{1} \cdot t}-e^{-\alpha_{2} t}\right)
$$

O tempo de frente e de cauda da onda de impulso é determinada pelas constantes de Towsend, constantes de tempo $\alpha_{1}$ e $\alpha_{2}$. Manipulando-se tais parâmetros, é possível observar formas de ondas com frentes de 1,2 $\mu \mathrm{s}$ e tempos de meia onda iguais a $45 \mu$ s. O tempo de meia onda é medido desde o início da onda impulsiva, até o tempo em que a mesma decai a metade do valor de pico.

A câmara de carregamento é composta de material metálico, permitindo assim, uma perfeita blindagem do sistema de carregamento. No interior, encontram-se dois eletrodos, isolados eletricamente entre si e da própria blindagem. Os eletrodos superior e inferior são devidamente conectados à carga negativa e a terra, respectivamente.

No interior do cilindro os eletrodos superior e inferior, com 3 e 4 centímetros de diâmetro, respectivamente, sustentam a amostra somente pela ação da gravidade. A diferença no diâmetro dos eletrodos tem a função de 
evitar a formação de descargas elétricas laterais durante o processo de carregamento.

Acoplado ao sistema, encontra-se um divisor de tensão Tektronix 605 (1000:1) conectado a um osciloscópio digital KIKUSUI 7101A - $100 \mathrm{MHz}$. Esses equipamentos permitem a visualização e medição da forma de onda das tensões impulsivas que serão depositadas sobre o filme polimérico. No caso desse trabalho, o Teflon FEP.

\subsection{3 - Materiais comumente utilizados}

A tabela I lista os principais materiais que podem ser utilizados para a formação dos eletretos, divididos por classe e estrutura.

Tabela I. Exemplos de materiais com atividades piezelétricas.

\begin{tabular}{ccc}
\hline Classe & Material & Estrutura \\
\hline $\begin{array}{c}\text { Eletretos poliméricos não- } \\
\text { polares } \\
\text { Eletretos clássicos }\end{array}$ & $\begin{array}{c}\text { PTFE } \\
\text { FEP } \\
\text { Polómeletretos }\end{array}$ & $\begin{array}{c}\text { Cera de carnaúba } \\
\text { Regiões cristalinas } \\
\text { e amorfas }\end{array}$ \\
Cristais piezelétricos & PVDF & $\begin{array}{c}\text { Policristalina } \\
\text { Regiões cristalinas e } \\
\text { amorfas } \\
\text { Cerâmicas piezelétricas }\end{array}$ \\
\hline
\end{tabular}

Fonte: Extraído de Sessler (1998).

Este trabalho tem como objetivo a construção de termo sensores piezelétricos de dupla camada utilizando-se o Teflon FEP como matéria-prima. A escolha desse material se deu devido a sua estrutura ser composta por armadilhas superficiais, onde cargas elétricas negativas são facilmente aprisionadas e permanecem por longos anos. 
Esta capacidade exibida pelo filme fluoretado de teflon resulta em um alto coeficiente piezelétrico, quando carregado por uma tensão de impulso.

Entretanto, para que haja um efetivo controle das cargas elétricas aprisionadas, isto é, uma densidade superficial de carga controlada no interior da amostra sensorial, é necessária a formação de vacúolos gasosos (denominados universalmente de "voids") de maneira uniforme sobre a superfície polimérica.

Polímeros porosos e celulares não possibilitam tal controle, pois apresentam em sua configuração interna vacúolos aleatórios derivados do processo de fabricação do filme, o que inviabiliza o emprego destes para aplicações de controle fino, como dispositivos ópticos, sensores de precisão e outros.

\section{4 - Eletretos poliméricos de Teflon FEP}

Existem na indústria vários tipos de filmes poliméricos fluoretados, dentre eles, o Teflon PFA (Per Flúor Alcóxi), o Teflon PTFE (Poli Tetra Flúor Etileno), o Teflon FEP (Flúor Etileno Propileno) e os polímeros de flúor carbono, como o teflon amorfo AF.

Tais materiais são polímeros de características não polares e exibem uma alta impedância elétrica como característica intrínseca. Devido à excelente propriedade de armazenamento de cargas elétricas, são importantes nas aplicações como eletretos, em particular, na fabricação de microfones.

Em conseqüência disto, nas últimas décadas houve um crescente interesse no comportamento dinâmico, na distribuição de cargas e na estabilidade de cargas elétricas presentes nos filmes, bem como a curva de descarregamento apresentada por eles, principalmente o Teflon FEP.

Esta pesquisa utilizar-se-á do Teflon FEP devido ao seu alto poder de retenção de cargas superficiais. Como será abordado, este polímero se comporta como um excelente aprisionador de cargas elétricas por exibir, 
microscopicamente, armadilhas capazes de reter cargas elétricas negativas e positivas, dependentes diretamente do campo elétrico aplicado.

A presença predominante de armadilhas superficiais se dá devido à peculiaridade do Teflon FEP apresentar uma estrutura molecular anisotrópica. Estas armadilhas se apresentam como rasas e/ou profundas na superfície do filme polimérico. As denominadas rasas tendem a aprisionar cargas elétricas de potencial positivo, ao passo que, as profundas, aprisionam cargas elétricas de potencial negativo quando da aplicação de uma alta tensão negativa sobre o filme.

A tabela abaixo apresenta alguns materiais, bem com suas abreviações, estruturas e ligações químicas. 
Tabela II. Materiais poliméricos.

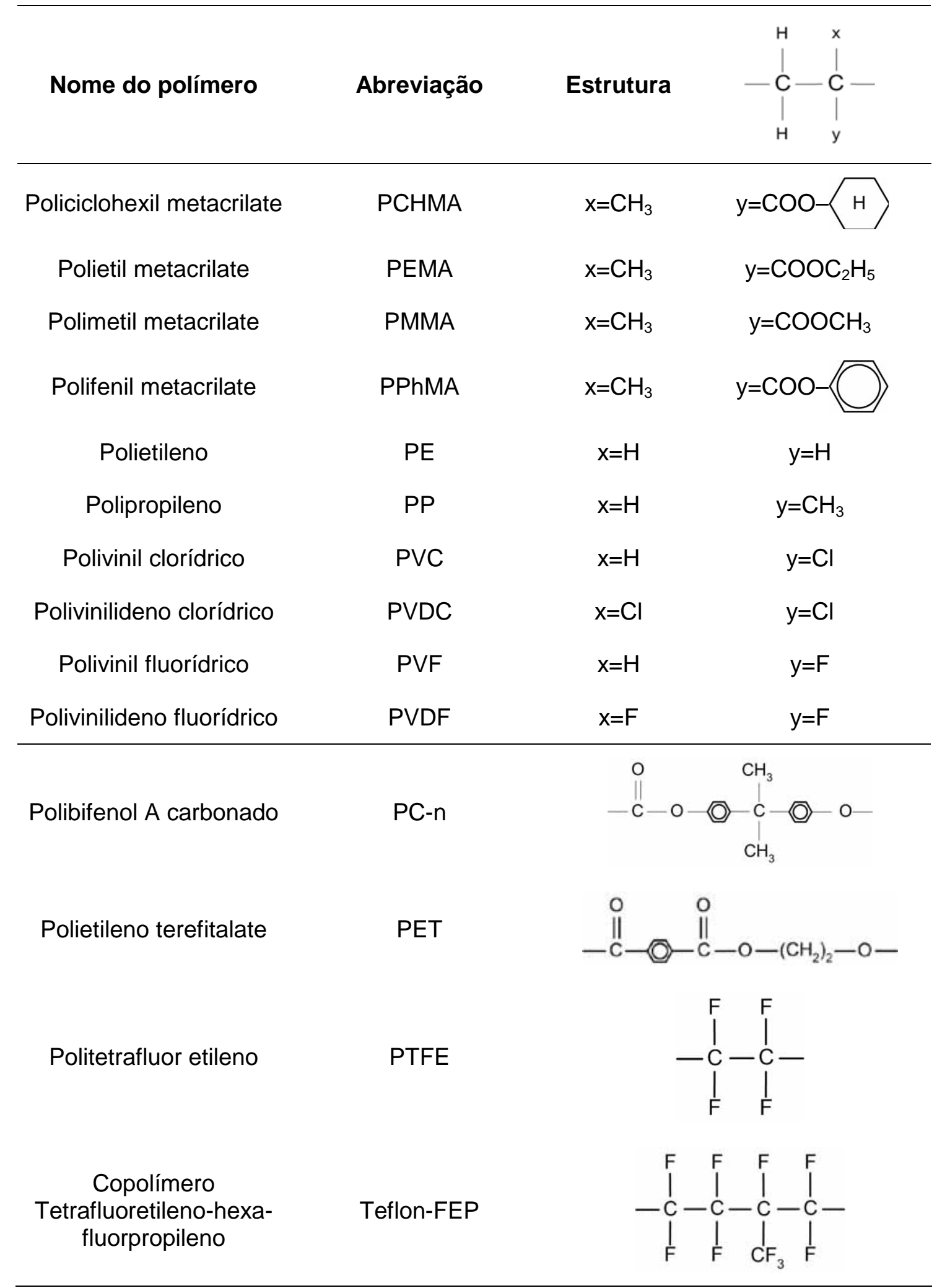

(continua na próxima página) 
(continuação da Tabela II)

\begin{tabular}{ccc}
\hline Nome do polímero & Abreviação & Estrutura \\
\hline $\begin{array}{c}\text { Copolímero } \\
\text { Tetrafluoretileno-per- } \\
\text { fluormetoxietilen }\end{array}$ & Teflon-PFA & \\
\hline
\end{tabular}

Fonte: Elaborada por J. van Turnhout (SESSLER, 1998)

No Teflon FEP, as cargas negativas depositadas em armadilhas profundas tendem a permanecer aprisionadas por um longo período de tempo, pois a energia de ativação dessas armadilhas é da ordem de 1,2 eV. Segundo Rodrigues (2003), a profundidade das cargas aprisionadas se situa entre zero e $0,5 \mu \mathrm{m}$.

As cargas positivas, após um processo de carregamento por campo elétrico negativo, ficam aprisionadas em armadilhas superficiais rasas e, com isso, são facilmente perdidas ao meio, pois a energia de ativação destas armadilhas é menor. Quando carregados por um processo de polaridade positiva, Sessler (1998, p.15) afirma que tanto o Teflon FEP como o Teflon PFA apresentaram uma taxa de diminuição das cargas elétricas acentuada, independente do tipo de carregamento utilizado. Para este material, as cargas de polaridade negativa apresentam maior estabilidade.

De fabricação e patente da DuPont, o Teflon FEP e o PFA podem ser encontrados em diferentes espessuras, porém as espessuras mais comumente utilizadas para a formação de termo eletretos são as de 50 e 75 micrômetros.

Hillenbrand (2000) desenvolveu estudos com filmes de Polipropileno (PP), aplicando uma pressão direta sobre o mesmo, obtendo um coeficiente piezelétrico inverso da ordem de $220 \mathrm{pC} / \mathrm{N}$, em uma faixa de freqüência entre zero e $10 \mathrm{kHz}$.

Foi assumido, para efeito teórico, que a distribuição de cargas no PP é de maneira plana e está confinada apenas nas superfícies do material, 
desprezando-se qualquer densidade de cargas volumétricas. Entretanto, sabese que o PP é um polímero poroso, com um difícil controle de cargas em seu interior.

O laboratório de Medidas e Padrões da Escola de Engenharia de São Carlos utilizou um sanduíche de dupla camada de Teflon FEP para confecção de termo eletretos de Teflon FEP como transdutores piezelétricos. Rodrigues (2003) obteve um coeficiente $d_{33}$ da ordem de $200 \mathrm{pC} / \mathrm{N}$, mensurado de maneira direta.

Informações técnicas sobre as propriedades do filme polimérico de Teflon FEP, disponibilizadas pelo fabricante, estão dispostas no anexo A.

\subsection{1 - Campo elétrico no interior da amostra}

O transdutor piezelétrico de Teflon FEP é um polímero constituído de duas folhas do filme polimérico, separadas por interstícios gasosos, neste caso, o ar atmosférico.

No modelo da figura 5, adaptado de Hillenbrand (2000), as diversas camadas que compõem a amostra são consideradas planas e paralelas entre $\mathrm{si}$,

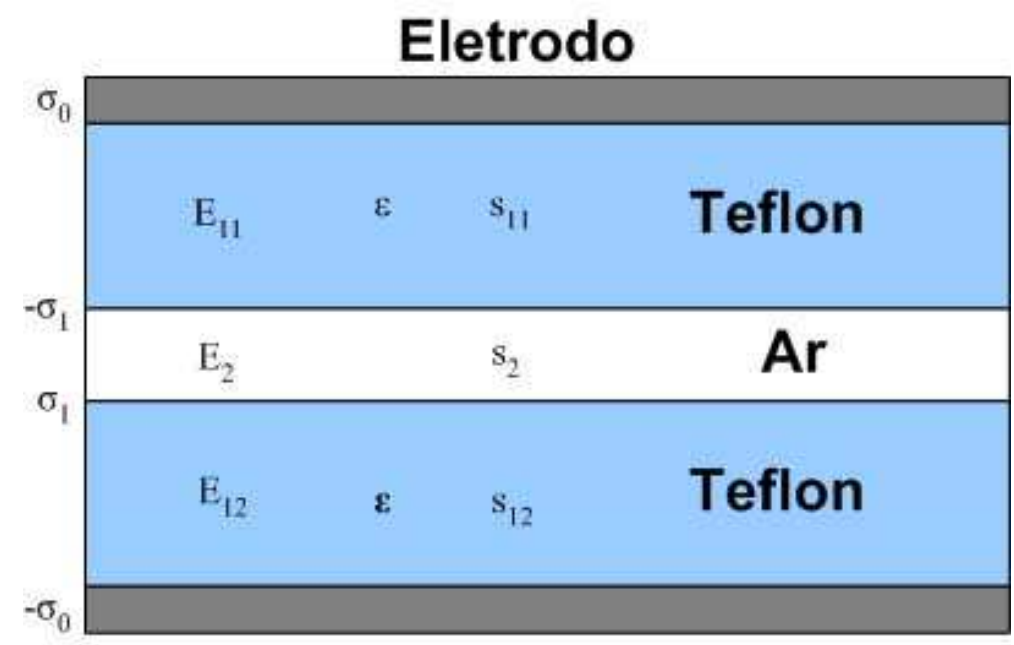

\section{Eletrodo}

Figura 5 - Esquema de uma amostra sensorial de dupla camada. 
onde $\sigma$ é a densidade superficial de cargas entre as camadas, $\boldsymbol{E}$ representa 0 valor do campo elétrico em cada camada e $s$ é a espessura da respectiva camada.

A densidade de cargas nas superfícies opostas dentro do interstício de ar tende a ser igual em módulo, pois as cargas elétricas positivas e negativas aprisionadas foram originadas através de impulsos elétricos durante o processo de carregamento.

O campo elétrico $\boldsymbol{E}$ pode ser obtido através das leis de Gauss e Kirchhoff, segundo a relação abaixo. Para o lado superior da camada de ar, a lei de Gauss pode ser escrita como:

$$
-\varepsilon E_{11}+E_{2}=\sigma_{1} / \varepsilon_{0}
$$

Aplicando-se a segunda lei de Kirchhoff para as demais interfaces, curtocircuitando-se os terminais da amostra, vem:

$$
s_{11} E_{11}+s_{2} E_{2}+s_{12} E_{12}=0
$$

Portanto, o campo elétrico no interior dos filmes poliméricos será o mesmo

$$
E_{11}=E_{12}=E_{1}
$$

onde, 


$$
E_{1}=-\left[\varepsilon_{0}\left(s_{1}+\mathcal{E} s_{2}\right)\right]^{-1} s_{2} \sigma_{1}
$$

e,

$$
E_{2}=\sigma_{1} / \varepsilon_{0}-\left[\varepsilon_{0}\left(s_{1}+\varepsilon s_{2}\right)\right]^{-1} \mathcal{E} s_{2} \sigma_{1}
$$

sendo $s_{1}=s_{11}+s_{12}$ a espessura dos filmes aqui representados.

\subsection{2 - Resposta elétrica da amostra}

A figura 5 representa o modelo ideal de uma amostra sensorial. A carga elétrica presente no eletrodo superior desta amostra é dada pela equação abaixo.

$$
\sigma_{0}=-\varepsilon_{0} \varepsilon_{1} E_{1}
$$

$\mathrm{Na}$ condição de curto-circuito, a resposta elétrica do sensor piezelétrico, neste modelo matemático, dependerá da deformação aplicada sobre o filme polimérico pela ação de uma força externa qualquer. Quando a espessura variar, o campo elétrico nas camadas da figura 5 sofrerá uma variação proporcional e a carga nos eletrodos se deslocará, equalizando o potencial nos filmes, segundo a equação abaixo.

$$
\frac{\partial \sigma_{0}}{\partial \sigma_{2}}=\varepsilon \frac{s_{1} s_{2} \sigma_{1}}{s_{2}\left(s_{1}+\mathcal{E} s_{2}\right)^{2}}
$$


Nos casos quase estáticos, Hillenbrand (2000) define que a constante piezelétrica de uma amostra sensorial é dada pela diferença finita abaixo,

$$
d_{33}=\frac{\Delta \sigma_{0}}{\Delta p}=\frac{\varepsilon s}{Y} \frac{s_{1} s_{2} \sigma_{1}}{s_{2}\left(s_{1}+\varepsilon s_{2}\right)^{2}}
$$

onde $Y$ representa o módulo de Young do teflon e $\Delta p$ é a força aplicada no filme, dada por:

$$
\Delta p=\frac{\Delta s_{2} Y}{s_{1}+s_{2}}
$$

Hillenbrand também desenvolve uma análise similar para a condição de circuito aberto, onde define a sensibilidade da amostra, denominada de $g_{33}$, como sendo,

$$
g_{33}=\frac{\Delta E}{\Delta p}=\frac{1}{\varepsilon_{0} Y} \frac{s_{1} s_{2} \sigma_{1}}{s_{2}\left(s_{1}+\varepsilon s_{2}\right)}
$$

Para estudos de microfones capacitivos, este parâmetro é definido como sendo a sensibilidade do instrumento.

Finalizando, para uma condição onde o circuito encontra-se alimentado com uma tensão $V$, as equações acima são válidas, porém segundo o modelo matemático aplicando a segunda lei de Kirchhoff, vem:

$$
\left(s_{11}+s_{12}\right) E_{1}+s_{2} E_{2}=-V
$$


Para a medição de coeficientes piezelétricos quase estáticos, Rodrigues (2003) utilizou um sistema capacitivo onde as cargas elétricas geradas nas amostras eram transferidas ao capacitor e mensuradas por um osciloscópio, segundo a relação abaixo:

$$
d_{33}=C \cdot \frac{V_{m}}{F}
$$

onde $V_{m}$ representa o pico de tensão observado em mili Volts e $F$ a força aplicada em Newton.

O diagrama de medições desenvolvido por Rodrigues (2003) pode ser observado na figura 7 .

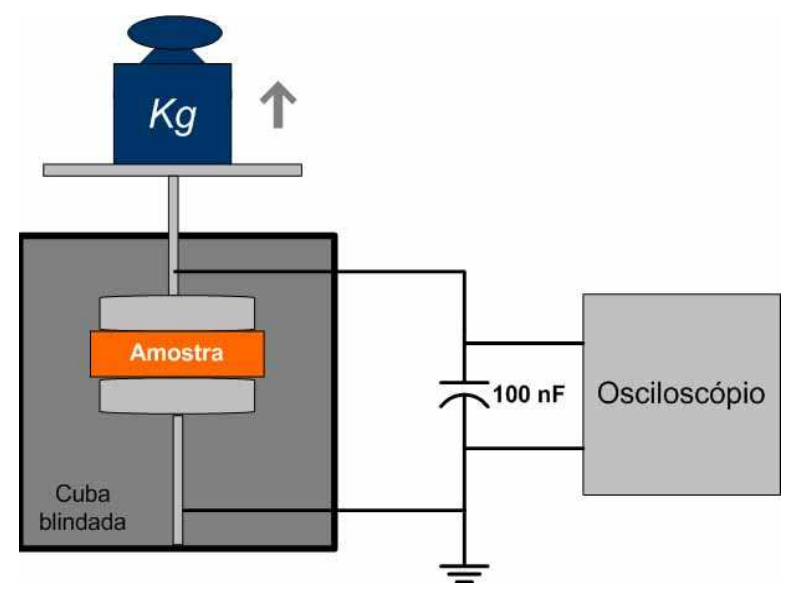

Figura 6 - Sistema de medição para coeficientes piezelétricos estáticos.

Este trabalho terá como foco principal a fabricação de amostras de dupla camada de Teflon FEP com interstícios gasosos uniformes em seu interior, para fins de caracterização piezelétrica, $d_{33}$.

O modelo matemático teórico de um termo sensor piezelétrico de Teflon FEP está sendo desenvolvido paralelamente por Cláudio Vara de Aquino, em seu trabalho de doutorado, validando-se os resultados piezelétricos avaliados neste trabalho. 


\section{3 - TRANSDUTORES PIEZELÉTRICOS DE TEFLON FEP}

A intenção deste capítulo é fornecer ao leitor uma breve visão dos termo sensores de Teflon FEP fabricados até o presente momento por Rodrigues (2003), suas características e respostas, bem como fazer inferências sobre os defeitos ali apresentados, construindo-se assim uma base sólida para o desenvolvimento desta dissertação de mestrado.

Este quadro é de vital importância para a motivação e continuidade deste trabalho, tendo em vista que esse é um campo vasto, com ramificações a serem exploradas.

A proposta desta pesquisa envolve tão somente o desenvolvimento de melhorias nos sensores produzidos atualmente, originando um produto com condições favoráveis a uma caracterização estática e dinâmica, obtendo-se um completo controle de resposta frente a um nível controlado de cargas elétricas superficiais.

Uma produção industrial exige um nível de estabilidade e confiabilidade muito superior a de um processo artesanal, como o desenvolvido até 0 presente momento. Portanto, este desafio intenta projetar um sistema de fabricação de dispositivos piezelétricos totalmente inovador, incorporando novas idéias e sugestões, principalmente no que tange à formação de vacúolos gasosos de maneira uniforme. 
O processo de fabricação atual dispensa qualquer emprego de maquinário especializado; porém, da ação humana resulta um produto muito frágil e de fácil destruição frente a um stress mecânico excessivo.

O novo processo de fabricação não anulará a tecnologia empregada no procedimento atual (artesanal), mas pretende incorporar novos conceitos, com o objetivo de implementar um fino controle das dimensões do dispositivo a ser produzido, a fim de poder considerar uma deposição superficial de cargas constante, produzindo um transdutor com uma ampla faixa de operação e, principalmente, contendo microbolhas uniformes, tendo como foco a produção em série de um dispositivo de qualidade.

Este controle sobre a formação dos vacúolos gasosos (microbolhas de ar atmosférico) no interior do material polimérico tende a ser um processo totalmente inovador, pois, no campo da ciência e tecnologia ainda não existe um perfeito controle dos interstícios de ar.

Pesquisadores em todo o mundo estão em busca de novas técnicas e materiais, com o objetivo de se fabricarem sensores e atuadores com um coeficiente piezelétrico $\left(d_{33}\right)$ cada vez maior, porém não se tem conhecimento de publicações desses feitos com uma densidade superficial de carga controlada. Agrega-se a isto $\mathrm{o}$ valor de os transdutores de Teflon FEP fornecerem respostas cada vez mais confiáveis e repetitivas.

Um trabalho de mestrado, paralelamente a este, desenvolvido por Altafim, R.A.P., se concentra no desenvolvimento de um processo de medição a fim de caracterizar dinamicamente o transdutor com densidade superficial de carga controlada, fruto deste trabalho.

Portanto, o objetivo é desenvolver um processo de produto repetitivo e estável, onde a confiabilidade seja um ingrediente prioritário, obtendo-se um completo controle da quantidade e qualidade de microbolhas gasosas presentes na área útil do transdutor, bem como o volume de ar dispensado a cada vacúolo. 


\section{1 - Sensor multicamada de Teflon FEP produzido de maneira artesanal}

Rodrigues (2003) desenvolveu o primeiro protótipo de um sensor piezelétrico elaborado com folhas de Teflon FEP, idealizado por Altafim (1990). Somente nas últimas décadas, o Teflon FEP tem se estabelecido como objeto de pesquisa na área da piezeletricidade. Com o advento dos polímeros, outros materiais eram preferencialmente utilizados em todo o mundo, a exemplo, o celular Polipropileno (PP), o poroso Poli Tetra Flúor Etileno (PTFE), o ferroelétrico Poli Fluoreto de Vinilideno (PVDF), dentre outros.

Elaborado de maneira totalmente artesanal, o sensor praticamente consiste em um "sanduíche", contendo duas folhas de Teflon FEP de 75 micrômetros de espessura cada uma, é preso a um bastidor circular de alumínio, produzindo uma área útil de aproximadamente cinco centímetros de diâmetro.

Os eletrodos são constituídos de alumínio, oriundos de papel alumínio comum utilizado no dia-a-dia. Para a formação dos vacúolos gasosos entre as paredes do sensor, um spray de verniz foi utilizado, formando interstícios de ar interno às folhas de teflon, contendo uma espessura da ordem de dez micrômetros. Os eletrodos de alumínio são conectados às paredes externas do sensor polimérico, utilizando-se o mesmo verniz empregado na formação dos vacúolos, aumentando, assim, o número de interstícios de ar na amostra sensorial.

O esquema abaixo denota a formação completa do dispositivo fabricado. 


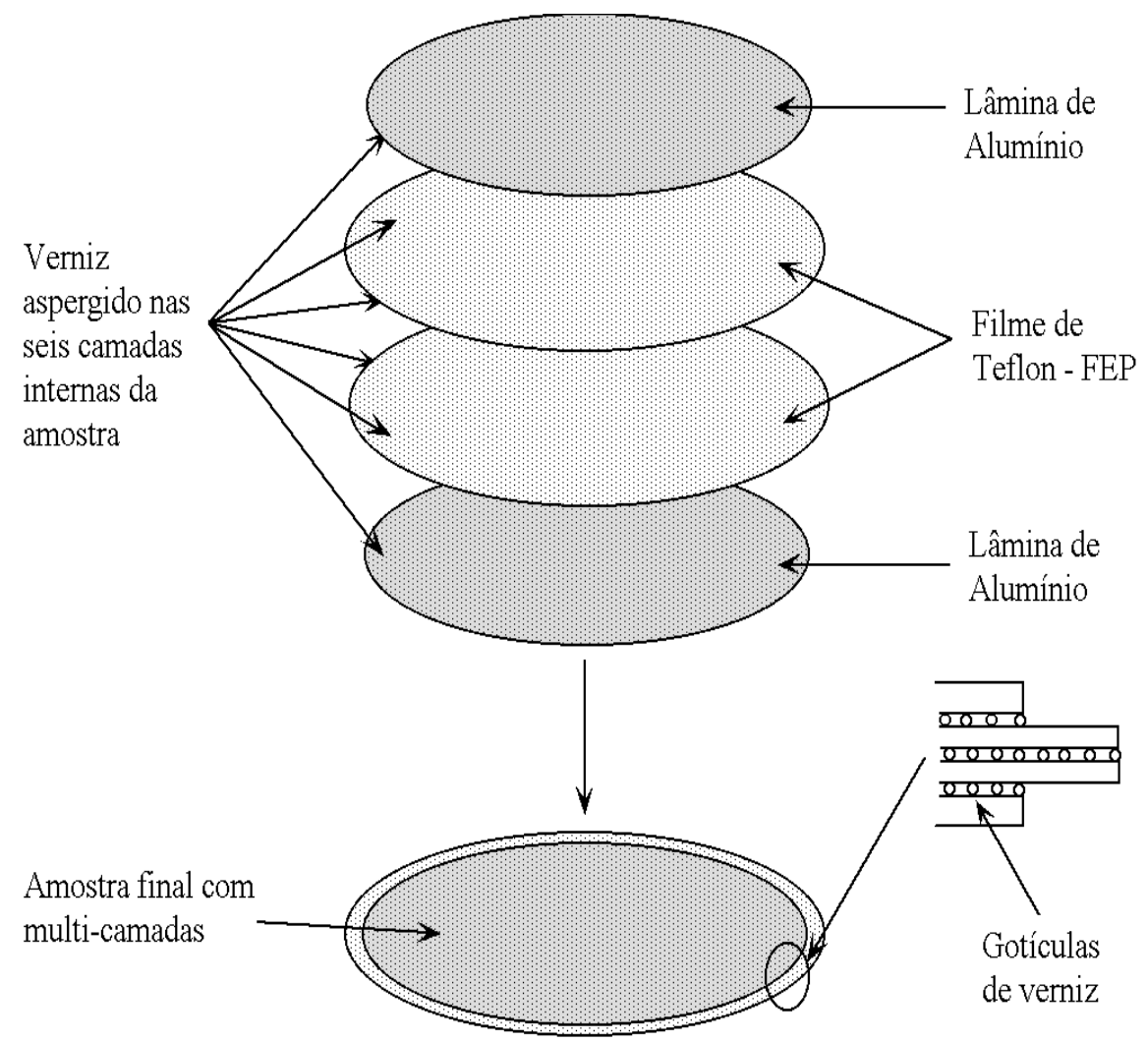

Figura 7 - Esquema de um sensor piezelétrico multicamadas de Teflon FEP com eletrodos de alumínio e vacúolos gasosos de verniz.

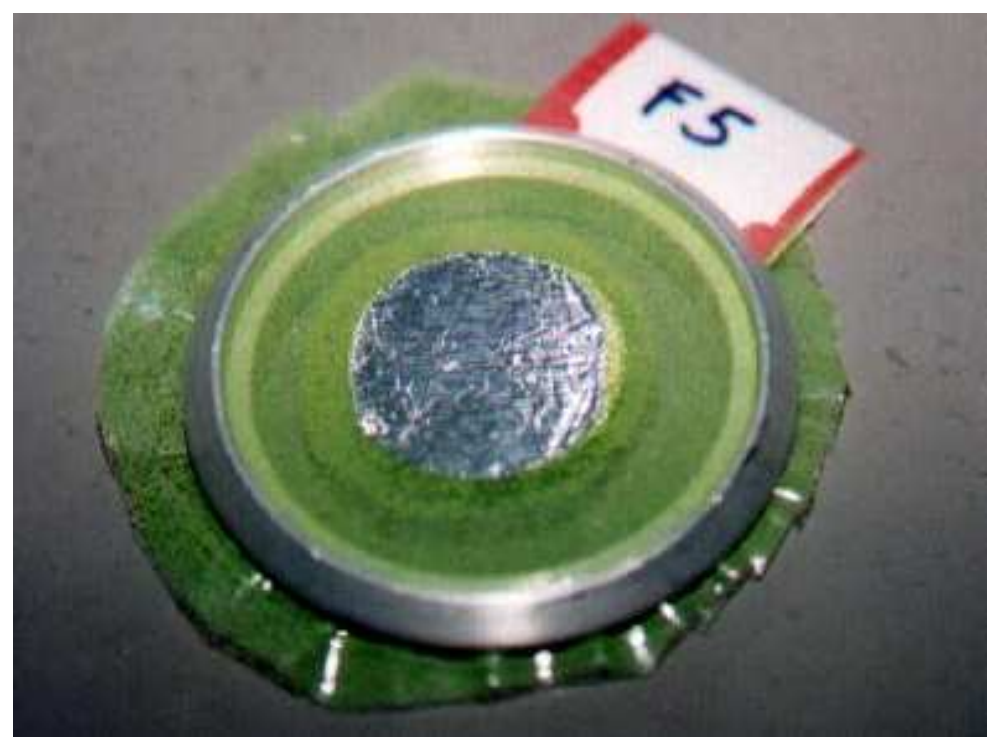

Figura 8 - Amostra sensorial de Teflon FEP fabricada no laboratório da Escola de Engenharia de São Carlos - EESC/USP, segundo o esquema da figura anterior. 
Diversas amostras sensoriais foram produzidas e testadas para se constatar que este é um processo repetitivo, aumentando assim a confiabilidade do produto final. Para tanto, a temperatura e a umidade do ar foram mantidas em aproximadamente $25 \stackrel{\circ}{\mathrm{C}}$ e $55 \%$, respectivamente.

\section{2 - Resultados experimentais dos sensores produzidos de maneira artesanal}

Dentre os vários métodos de carregamento empregados mundialmente, os sensores, sem carga inicial, tiveram suas cargas propiciadas por um carregamento do tipo impulsivo, idealizado e validado por Altafim $(1992,1998)$, sob uma curva característica de 1,2 por 50 micro segundos, curva esta predominante de uma descarga atmosférica, como citado no capítulo anterior.

A resposta estática do sensor piezelétrico revelou que a tecnologia empregada nas folhas de teflon resultam em altos valores piezelétricos, da ordem de $200 \rho \mathrm{C} / \mathrm{N}$, para um pico de tensão de $30 \mathrm{mV}$, como observado na figura abaixo. Esses níveis são comparáveis às diversas publicações desenvolvidas por pesquisadores de renome da atualidade, culminando nos resultados apresentados por Altafim (2003).

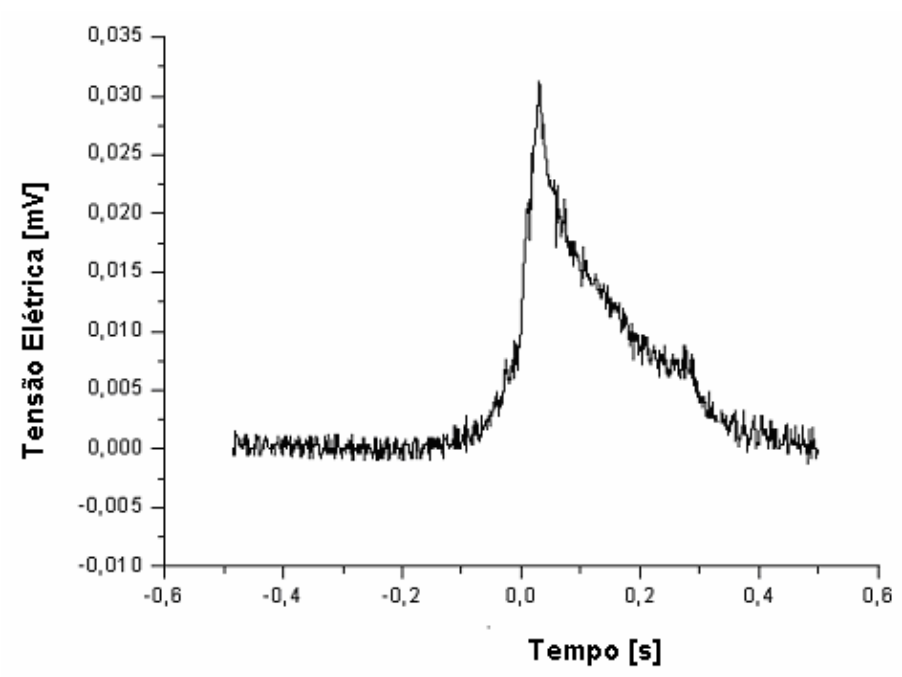

Figura 9 - Resposta elétrica de um transdutor piezelétrico multicamadas de Teflon FEP fabricado na EESC/USP. 
Como a tensão negativa de carregamento também influencia na quantidade de cargas superficiais depositadas na superfície do filme polimérico, o gráfico abaixo demonstra uma região linear e crescente para tensões de carregamento inferior a $8 \mathrm{kV}$. Excedendo-se este valor, o sistema atinge um patamar onde as cargas não são mais armazenadas, devido às descargas reversas de Pachen (back-discharges).

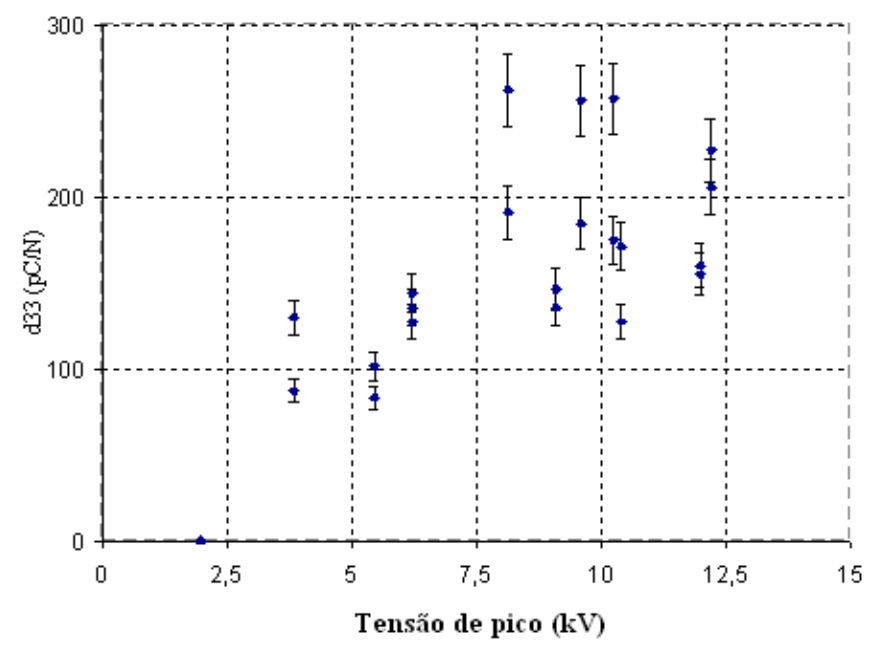

Figura 10 - Resposta piezelétrica de amostras de Teflon FEP carregadas com diferentes níveis de tensão elétrica negativa.

Mesmo diante dos altos níveis piezelétricos exibidos por esses sensores, uma série de problemas formou um gargalo para uma produção industrial, necessitando-se assim de uma reformulação completa no processo de fabricação, na tentativa de amenizar os problemas abaixo descritos.

\section{3 - Análise crítica do sensor existente}

Diversas foram as críticas apresentadas ao trabalho artesanal de fabricação, sendo a principal delas a falta de controle da dimensão intersticial entre as paredes do sensor piezelétrico.

Em contrapartida, como a tecnologia empregada acarretou uma resposta sensorial satisfatória, a motivação nesta pesquisa veio a aumentar, com o 
objetivo de superar os desafios encontrados e mais bem descritos nos itens subseqüentes.

\subsection{1 - Faixa de linearidade}

O sensor apresentou uma curva, em cujo início se pode inferir certa linearidade quase estável, porém, pela deficiência de pontos colhidos e falta de metodologia adequada, faz-se necessário um aprimoramento dos processos de medição (estático e dinâmico; direto e indireto), bem como o de fabricação, permitindo assim que os novos produtos não apresentem variação na estrutura de formação dependente do stress mecânico aplicado. Isso permitirá que novos resultados apresentem índices com maior nível de confiabilidade.

\section{verniz \\ 3.3.2 - Compressão dos vacúolos internos formados com}

O verniz empregado na fabricação dos interstícios de ar no interior das paredes poliméricas sofre diretamente a ação de forças aplicadas em qualquer uma das superfícies.

Considerando-se o caso estudado, a força piezelétrica na direção perpendicular à superfície da amostra, também conhecida como $d_{33}$, atinge diretamente os microscópicos pigmentos da "cola", que, frente a um esforço repetitivo, acabam por perder suas propriedades mecânicas e elásticas, não havendo recuperação do seu estado inicial. Em vista disso, há uma variação na dimensão dos interstícios gasosos formados no interior da amostra sensorial, bem como uma perda de carga elétrica, devido à recombinação das cargas positivas e negativas.

Experiências revelam que 0 índice piezelétrico de uma amostra elaborada com verniz industrial comum, com aspersão artesanal, exibe uma resposta inicial satisfatória. Entretanto, seu desempenho ao longo do tempo é comprometido. 
O verniz utilizado restringe a faixa de operação em freqüência do sensor piezelétrico devido a modificações em suas propriedades internas quando exposto a diferentes temperaturas e níveis de umidade, comprometendo assim a área útil do capacitor formado pelas membranas poliméricas.

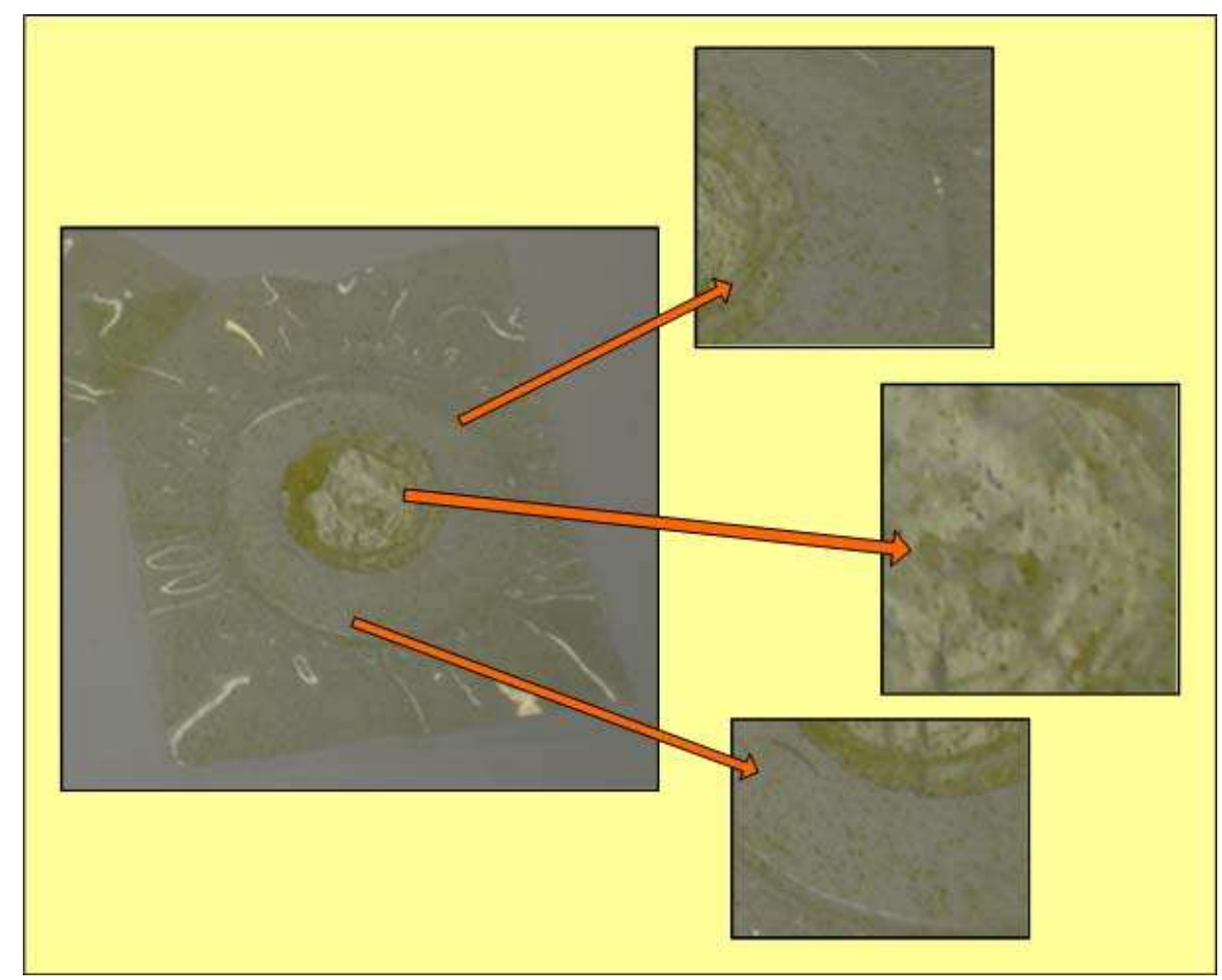

Figura 11- Transdutor piezelétrico com detalhes para as bolhas de verniz deterioradas.

Devido a esses problemas inspecionados experimentalmente, Rodrigues (2003) concluiu que existe uma degeneração das microbolhas internas, afetando definitivamente o sensor, pela perda das cargas aprisionadas nas armadilhas superficiais.

\subsection{3 - Destruição do sensor piezelétrico frente a um stress prolongado}

Outro grande problema encontrado nos ensaios laboratoriais realizados é a degeneração completa do sensor piezelétrico de Teflon FEP, construído 
com verniz industrial comum. Não obstante à degeneração das microbolhas internas, variação da espessura do dielétrico interno e desprendimento das cargas elétricas, as próprias folhas transparentes de teflon sofrem um processo de descolagem, deixando a camada interna do sensor exposta ao ar atmosférico, facilitando, então, a perda das cargas elétricas para o meio ambiente, mediante recombinação destas com íons livres presentes no ar.

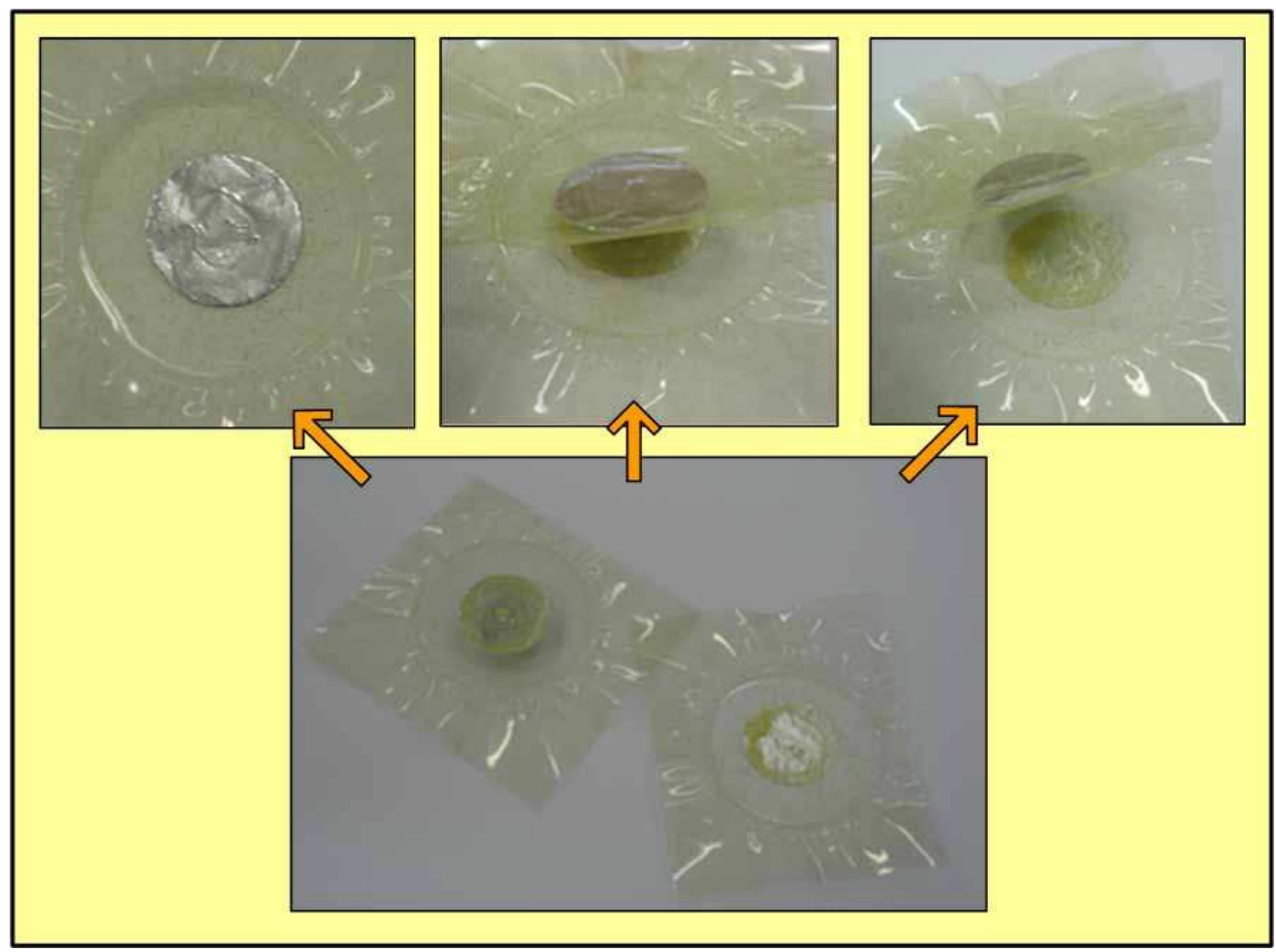

Figura 12 - Transdutores piezelétricos com detalhes para o fácil descolamento dos filmes poliméricos e dos eletrodos.

Para os eletrodos, o material condutor utilizado é suficiente, porém sua aderência ao teflon é muito fraca. $O$ verniz utilizado, mesmo que em diversos níveis de densidade sob a superfície da amostra piezelétrica, degrada-se e descola-se facilmente, expondo o sensor a uma situação de perda de eletrodos, influenciando no circuito de medição. Não se pode desprezar que a pequena área entre o eletrodo e a parede polimérica também representa uma grande perda para os estudos piezelétricos, uma vez que as duas camadas de 
vacúolos gasosos entre os eletrodos e a amostra sensorial formam um sistema capacitivo série. 


\section{4 - NOVO SENSOR PIEZELÉTRICO DENOMINADO TERMOFORMADO}

Os diversos problemas, citados no capítulo anterior, aliados à necessidade de se criar um processo mais bem adaptado à produção industrial em larga escala, e, que fosse também confiável, repetitivo, e, fornecesse um produto com uma durabilidade satisfatória, justificaram a continuidade dos estudos para o desenvolvimento de um novo processo tecnológico, a fim de se elaborar sensores piezelétricos, empregando a técnica de formação de vacúolos entre dois filmes de teflon. Esse processo será descrito nos itens subseqüentes.

\section{1 - Formação dos eletrodos}

O Teflon FEP, por ser um polímero classificado como antiaderente, cria dificuldades para a formação de eletrodos no sensor. A colagem de qualquer material condutor ou isolante no teflon torna-se extremamente difícil.

As primeiras amostras continham eletrodos de alumínio aderidos com verniz, mas, embora nos primeiros momentos apresentassem boas condições de fixação ao serem submetidas a um esforço repetitivo, como, por exemplo, um teste dinâmico, os eletrodos acabavam se descolando da superfície da amostra, indicando que o verniz também não oferece uma aderência satisfatória entre a folha de alumínio e o teflon. 
Neste trabalho, uma das primeiras preocupações foi então a de se definir um processo de fabricação que garantisse um eletrodo mais estável, com aderência superior.

Novas técnicas foram testadas com a finalidade de se aumentar a aderência do eletrodo de alumínio à superfície do filme polimérico, como descrito na tabela III:

Tabela III. Processos de fixação do eletrodo nos transdutores piezelétricos de Teflon FEP.

\begin{tabular}{|c|c|c|}
\hline Substância utilizada & Aplicação & Resultados e observações \\
\hline Colagem a quente & $\begin{array}{l}\text { Aplica-se o verniz nas duas } \\
\text { partes a serem unidas, } \\
\text { porém com elevada } \\
\text { temperatura e baixa } \\
\text { umidade. }\end{array}$ & $\begin{array}{l}\text { Não há melhorias na } \\
\text { aderência. Os eletrodos de } \\
\text { alumínio se descolam do } \\
\text { sensor facilmente. }\end{array}$ \\
\hline Cola de sapateiro & $\begin{array}{c}\text { Aplica-se a substância nas } \\
\text { duas partes a serem unidas } \\
\text { e, decorrido determinado } \\
\text { tempo suficiente para a } \\
\text { evaporação do solvente, é } \\
\text { feita a união do eletrodo } \\
\text { com o sensor. }\end{array}$ & $\begin{array}{l}\text { Nota-se uma maior } \\
\text { aderência em relação à } \\
\text { anterior, porém não resiste a } \\
\text { testes repetitivos e } \\
\text { dinâmicos (descolam). }\end{array}$ \\
\hline Coca-cola & $\begin{array}{c}\text { Aplica-se o refrigerante de } \\
\text { cola sobre as superfícies a } \\
\text { serem unidas e, decorrido } \\
\text { determinado tempo para } \\
\text { evaporação do excesso de } \\
\text { água, é feita a junção dos } \\
\text { materiais. }\end{array}$ & $\begin{array}{l}\text { Houve uma aderência } \\
\text { inferior aos demais casos, } \\
\text { com um processo de } \\
\text { secagem muito demorado. }\end{array}$ \\
\hline $\begin{array}{l}\text { Evaporação de alumínio } \\
\text { sobre a superfície do sensor }\end{array}$ & $\begin{array}{l}\text { A amostra sensorial, presa } \\
\text { diretamente ao bastidor de } \\
\text { alumínio, sofre um processo } \\
\text { de deposição de alumínio } \\
\text { evaporado, a alta } \\
\text { temperatura. }\end{array}$ & $\begin{array}{c}\text { Ao ser resfriado, retornando } \\
\text { à temperatura ambiente, } \\
\text { essa camada de alumínio } \\
\text { depositada torna-se rígida, } \\
\text { "endurecendo" as folhas do } \\
\text { sensor, ocasionando grande } \\
\text { perda na resposta, mesmo } \\
\text { que as cargas elétricas } \\
\text { estejam presentes em seu } \\
\text { interior. }\end{array}$ \\
\hline
\end{tabular}

(continua na próxima página) 
(continuação da Tabela III)

\begin{tabular}{|c|c|c|}
\hline Substância utilizada & Aplicação & Resultados e observações \\
\hline Conductive Epoxi ${ }^{1}$ & $\begin{array}{l}\text { Aplica-se a mistura sob as } \\
\text { partes a serem unidas e, } \\
\text { decorrido tempo de pré- } \\
\text { secagem da pasta } \\
\text { condutora, é feita a junção } \\
\text { das partes. }\end{array}$ & $\begin{array}{c}\text { É o melhor dentre os } \\
\text { processos acima descritos, } \\
\text { porém o eletrodo desprende- } \\
\text { se com o tempo. A pasta } \\
\text { condutora, além de } \\
\text { necessitar de importação, } \\
\text { possui um preço elevado } \\
\text { encarecendo o produto final. }\end{array}$ \\
\hline
\end{tabular}

Tendo em vista as técnicas examinadas para utilização do papel alumínio como eletrodo, constata-se que, apesar de sua excelente condição de elemento condutor e baixíssimo preço, a sua aderência ao teflon é muito fraca para garantir um produto confiável. Assim, após extensivos testes foi descartada a hipótese de se fabricarem eletrodos com esse material.

Passou-se então para um processo de vaporização de metal em câmara de alto vácuo, empregando-se o ouro como matéria-prima para os eletrodos. Neste processo, verificou-se uma excelente aderência do metal ao teflon, garantindo assim um excelente eletrodo condutor. Foi depositada uma camada de ouro com $10 \mu \mathrm{m}$ de espessura sobre a superfície superior e a inferior do sensor, que garantiu resistência ao sensor nos ensaios dinâmicos. Na Figura 14 observa-se um detalhe desse eletrodo. 


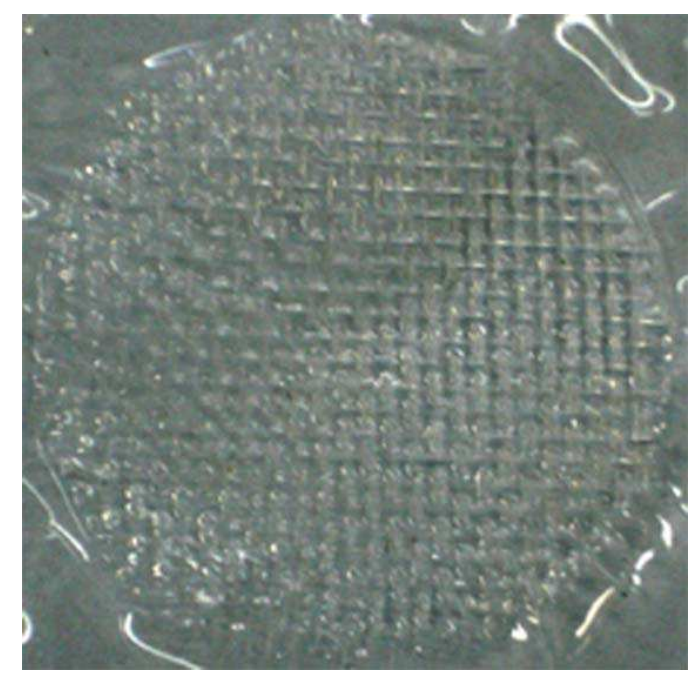

(a)

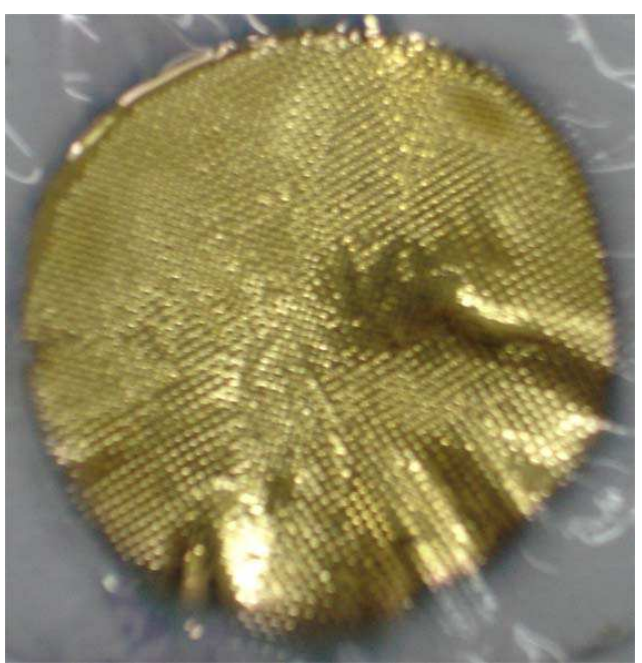

(b)

Figura 13 - Transdutores piezelétricos de Teflon FEP; (a) sem metalização; (b) com metalização a ouro de 10 nm.

Outra vantagem do processo de metalização, devida à perfeita aderência do metal à superfície do teflon, é a não formação de vacúolos de ar entre o eletrodo e o transdutor piezelétrico, como existia anteriormente. Com isso, torna-se possível melhor controlar o processo de deposição de cargas elétricas no interior da amostra.

A camada de ouro de $10 \mu \mathrm{m}$ depositada sobre as folhas de teflon não alteram o desempenho do sensor, isto é, as propriedades mecânicas e elásticas e, conseqüentemente, as elétricas não sofrem influência significativa. Como a resistência mecânica e a elasticidade da amostra sensorial são características intrínsecas das folhas poliméricas e não se alteram, não haverá distorções do sinal resultante da amostra.

Entretanto, como o ouro é um metal nobre, seu alto valor pode inviabilizar o custo de produção do sensor, razão pela qual também foi utilizado o alumínio e o estanho por esse processo, obtendo-se também excelentes resultados. 


\section{2 - Formação de bolhas de ar uniformes entre os filmes de teflon}

Os materiais porosos e celulares, como por exemplo, o Polipropileno (PP), não permitem um controle uniforme das cargas elétricas depositadas nos vacúolos, devido a sua estrutura molecular ser totalmente não uniforme, como observado na figura 14.

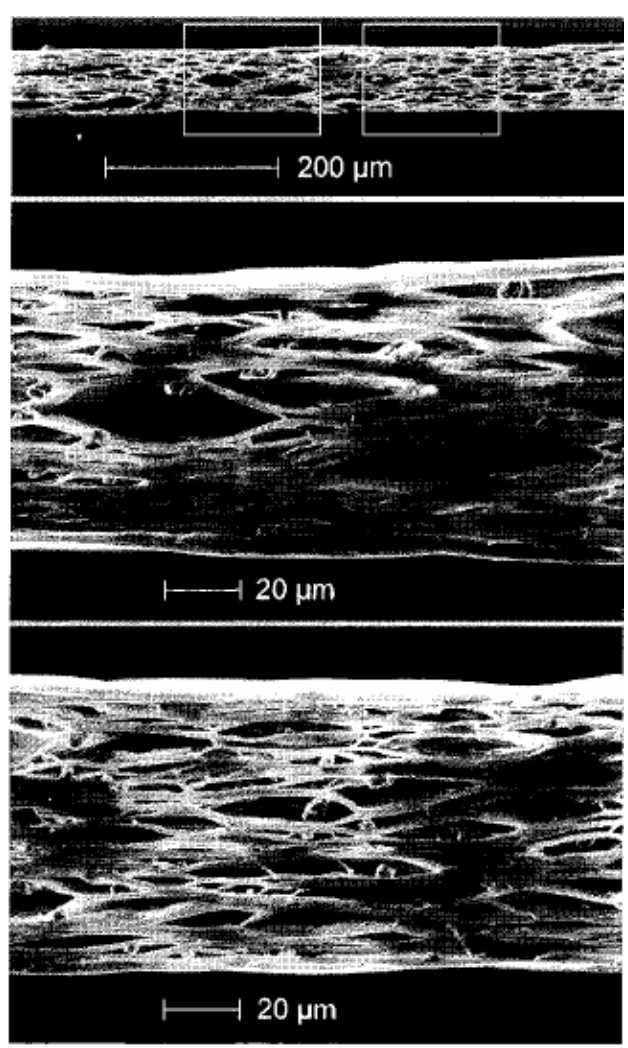

Figura 14 - Imagem de corte transversal feito em um filme celular PP de $70 \mu \mathrm{m}$ em duas posições (centro e inferior) feita com um microscópio SEM.

Objetivando criar um método que permitisse formar bolhas gasosas uniformes que facilitassem o controle da deposição das cargas elétricas em seu interior e conseqüentemente a polarização do material, foi empregado o Teflon Flúor Etileno Propileno (FEP), que apresenta um baixíssimo tempo de decaimento, superior a 500 anos.

As cargas elétricas presentes no interior do transdutor piezelétrico de Teflon FEP são aprisionadas em armadilhas profundas e rasas, pois este 
material é um polímero não poroso, conforme classificado por GerhardMulthaupt (1999). Portanto, a nanocamada de ar uniforme que se deseja obter entre as folhas poliméricas ocasionará uma grande influência no volume de cargas elétricas a serem aprisionadas na superfície do filme polimérico.

Os sensores desenvolvidos atualmente, tanto no Brasil quanto no restante do mundo, não exibem um fino controle dessa camada de ar, não permitindo, assim, uma atuação direta sobre a densidade de cargas elétricas superficiais presentes na amostra.

No sensor brasileiro, o verniz depositado artesanalmente sobre a superfície do polímero resulta em uma fina camada de gotículas que perfazem o papel de microbolhas no interior da amostra. Entretanto, as microbolhas se fixam de maneira totalmente aleatória sobre a superfície do sensor devido à deposição dessa camada ser de forma totalmente manual, bem como o bico do pulverizador utilizado para aspergir o verniz não ser ideal.

Devido a essa fina camada totalmente não uniforme prevalecer na fabricação dos transdutores piezelétricos, torna-se improdutiva uma produção em larga escala, pois cada unidade produzida apresentará diferentes níveis de microbolhas, permitindo assim resultados totalmente discrepantes na caracterização do produto final. 


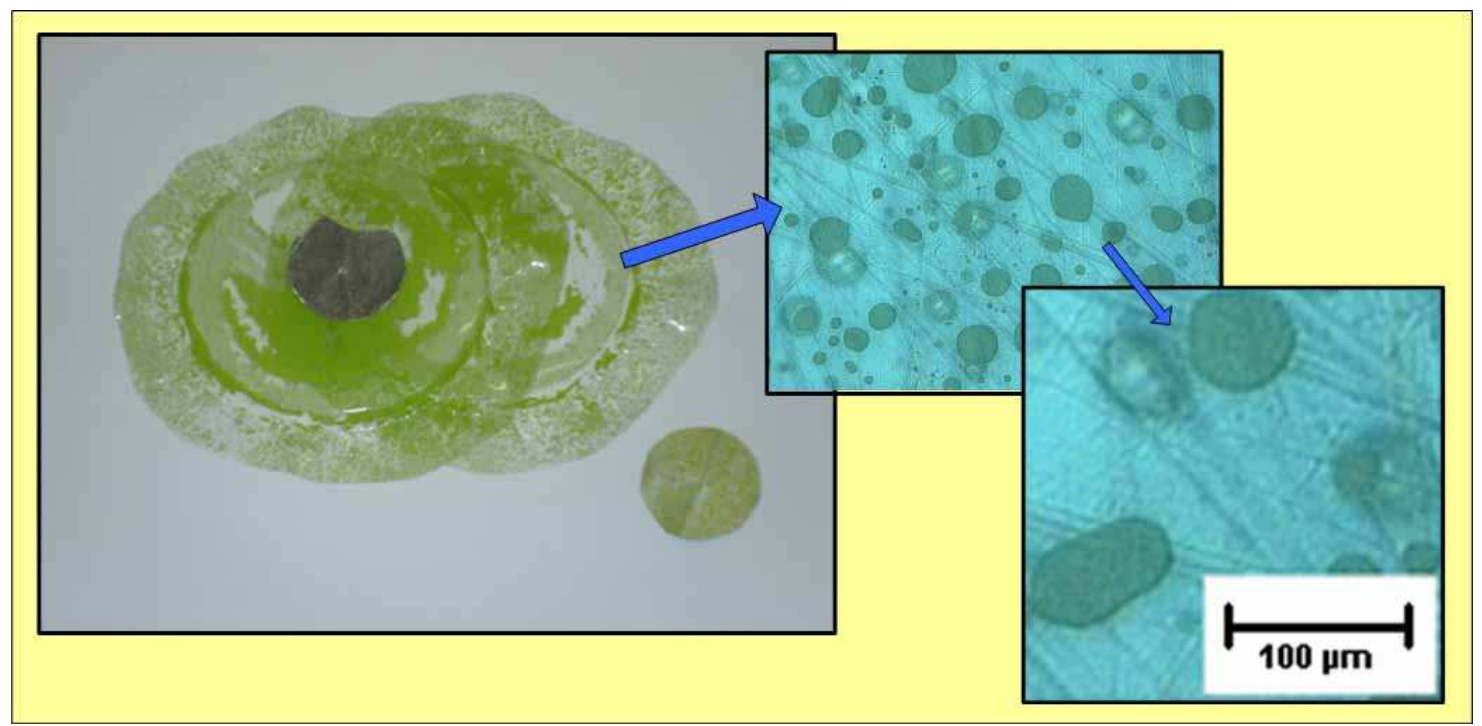

Figura 15 - Transdutor piezelétrico de Teflon FEP com detalhe para a não uniformidade do verniz aspergido e o fácil descolamento.

Dentre os pontos críticos que foram ponderados nesse novo processo de produção de sensores termoformados encontram-se:

> Definição da dimensão e forma do sensor piezelétrico;

> Área de formação das microbolhas (área útil do transdutor);

> Valor da espessura do filme a ser utilizado;

> Verificação das propriedades elétricas e mecânicas do dielétrico;

> Modelos de medição estática e dinâmica.

O problema principal consiste em distribuir homogeneamente as bolhas sobre a superfície do filme, de maneira que este não apresente perdas em suas propriedades. Para tanto, o verniz depositado de forma aleatória, que demonstrou altos índices piezelétricos foi descartado, pois apesar dos extensivos testes realizados, não se obteve uma camada uniforme de microbolhas sobre a superfície do polímero.

Como o coeficiente piezelétrico é uma grandeza absoluta, isto é, independe da área considerada, tomou-se uma área de aproximadamente 5,0 centímetros quadrados, dentro de um círculo de 2,5 centímetros de diâmetro, a 
fim de se projetar um sistema mecânico capaz de produzir microbolhas uniformes para confecção da amostra sensorial.

\section{3 - Primeiro protótipo laboratorial}

Inicialmente, foi construído um simples sistema de alavanca, oriundo de um espremedor de batatas comum, conforme ilustra a figura 16.

O princípio desse sistema consistia na aplicação de uma pressão manual a quente para unir duas folhas de teflon, sem que houvesse perda nas propriedades mecânicas da folha polimérica. Esse processo foi o que possibilitou a junção adequada, tendo em vista esse material ser não aderente, tornando inviável o emprego de qualquer espécie de "cola" ou outro produto químico. Entretanto, testes térmicos indicaram que a temperatura final deve sempre estar abaixo da temperatura de fusão do teflon, caso contrário este perde suas propriedades mecânicas e, conseqüentemente, as elétricas. Temperaturas acima do ponto de fusão do material acarretam a destruição do teflon, derretendo-o e fixando-o de forma não homogênea nos eletrodos do sistema de fabricação. 


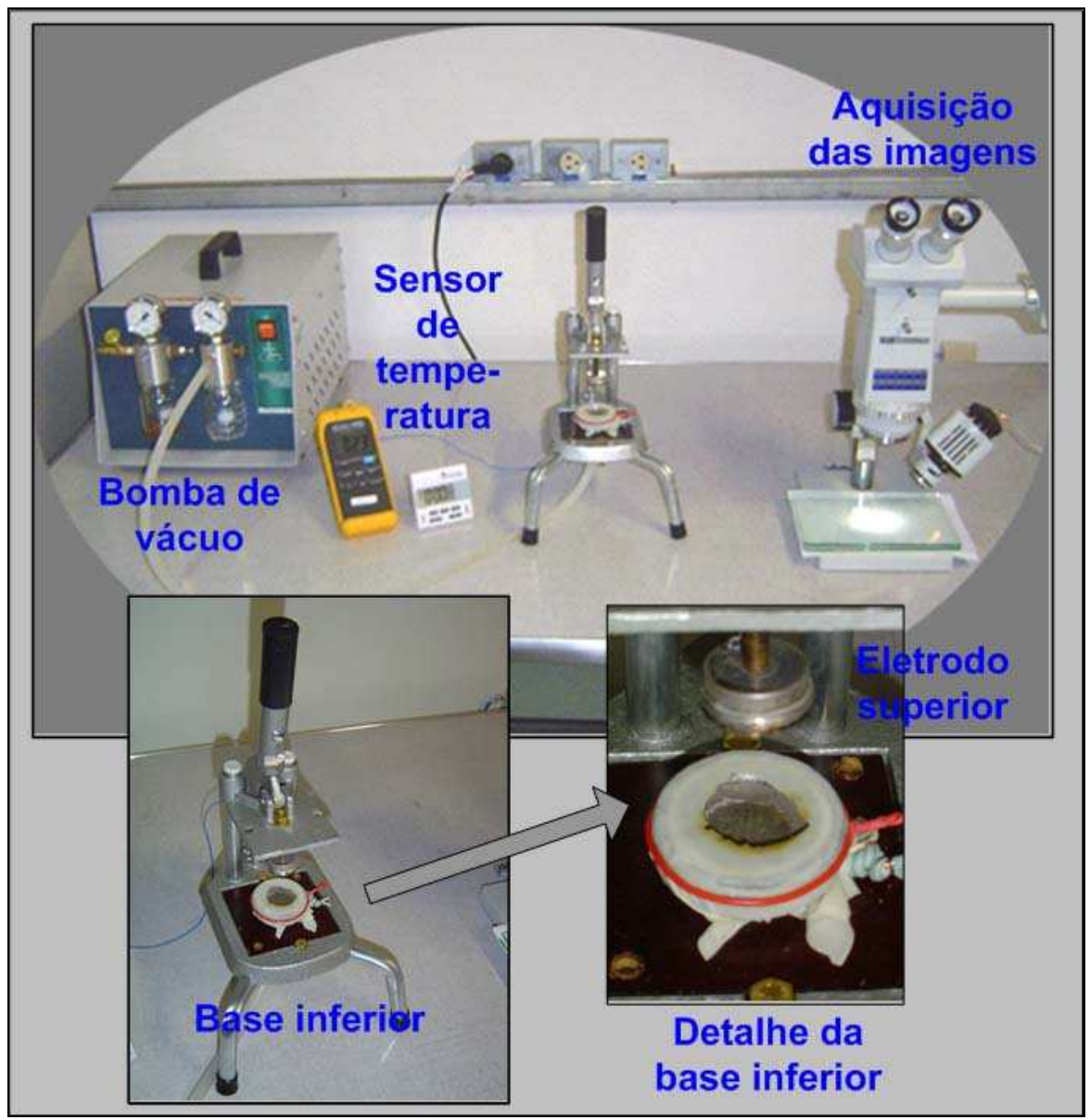

Figura 16 - Protótipo desenvolvido a partir de um espremedor de batatas com um sistema de aquisição de imagens, um sensor de temperatura e o sistema de vácuo.

Para a formação das microbolhas no interior da amostra sensorial, foi elaborado, inicialmente, um processo a vácuo, onde uma bomba de vácuo ocasionava deformações na superfície inferior da amostra, sugando o ar presente, abaixo do sensor, como mostrado na figura 16.

A folha de teflon inferior, deformada pela ação da bomba de vácuo, ao ser submetida a uma alta temperatura e pressão, produzidas principalmente pelo eletrodo superior, ocasionou uma pequena aderência de uma folha à outra.

O controle dessa aderência foi importante para garantir que se tivesse no produto final ar aprisionado no interior da amostra. São essas bolhas 
gasosas que irão conferir ao sensor suas excelentes propriedades piezelétricas, após ter sido carregado por um campo elétrico elevado.

Para que as folhas de teflon não fossem sugadas pelo sistema de vácuo, foi necessária a implantação de uma grade metálica com uma malha adequada, para suportar o sensor e a força exercida pelo conjunto. Assim, as microbolhas foram apenas criadas na folha inferior, permanecendo a folha superior levemente plana, por não ser praticamente sugada pelo sistema de vácuo. Nesse processo, o formato e tamanho das bolhas podem ser estabelecidos pela malha da grade metálica.

As figuras 17 e 18 mostram o resultado do processo de fabricação das amostras por um espremedor de batatas comum.
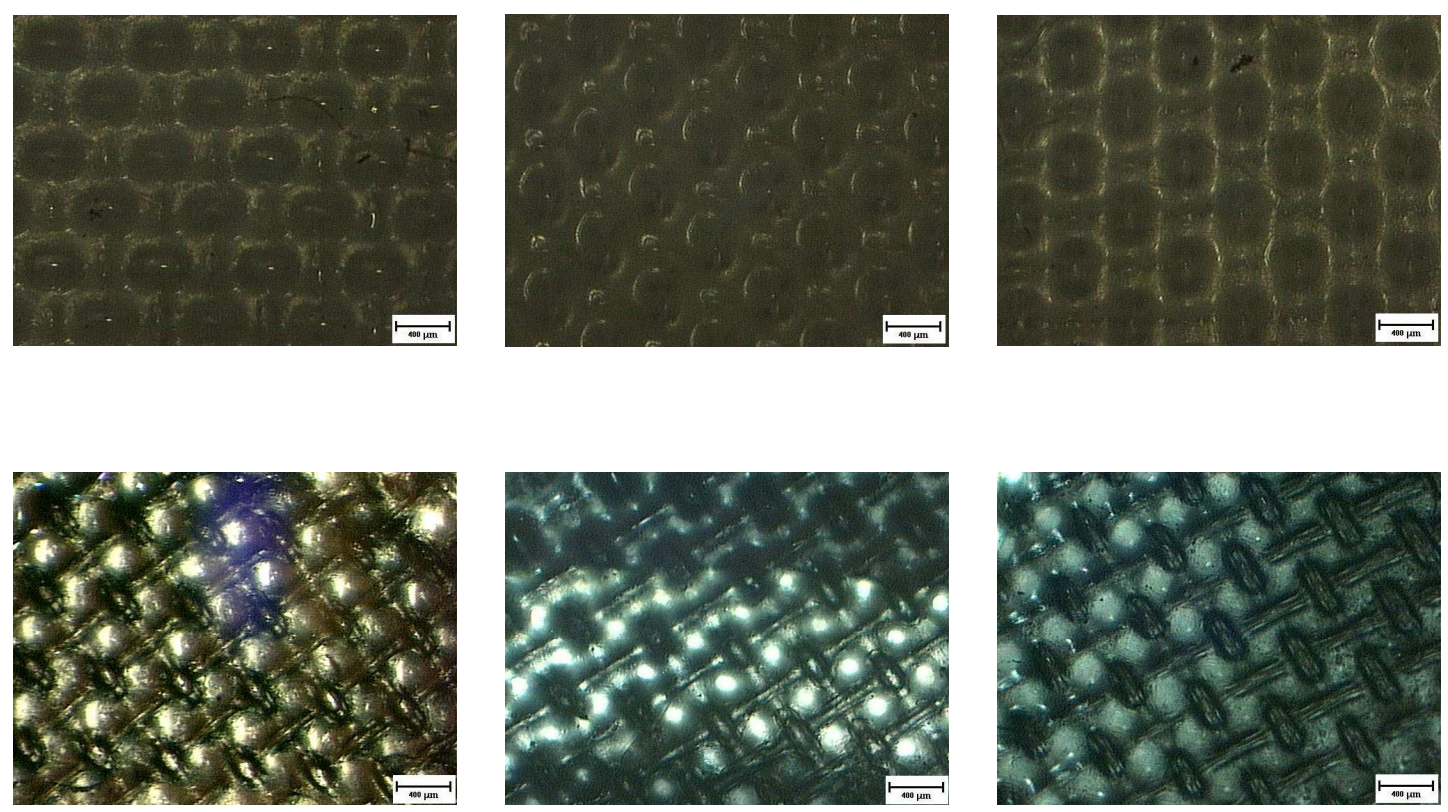

Figura 17 - Amostras sensoriais produzidas pelo primeiro protótipo; escala de $400 \mu \mathrm{m}$. 

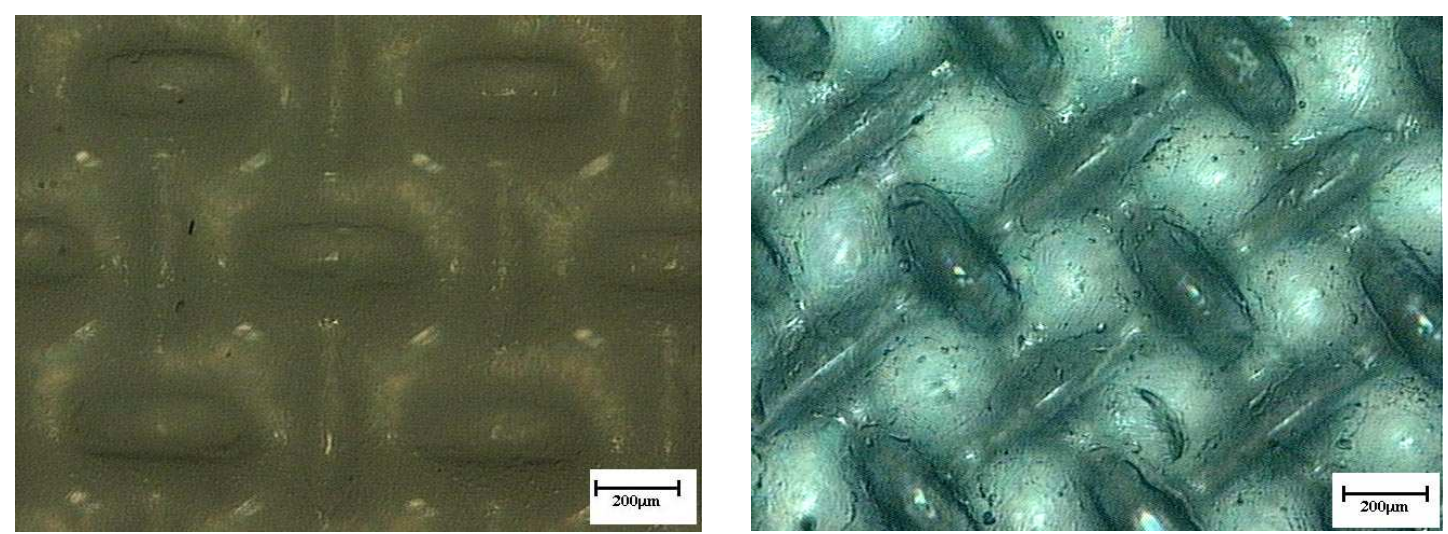

Figura 18 - Amostras sensoriais produzidas pelo primeiro protótipo; escala de $200 \mu \mathrm{m}$.

Os sensores piezelétricos produzidos por este sistema apresentaram altos níveis de coeficientes piezelétricos, demonstrando o sucesso do projeto. Porém, como o aquecimento do sistema foi feito com o auxílio de um maçarico, aplicando-se a chama diretamente sobre o eletrodo superior, mesmo que a temperatura tenha sido medida durante este processo é trabalhoso e dificulta sobremaneira a produção em série.

A medição da temperatura, nesse caso, foi feita por um termopar tipo $\mathrm{k}$ fixado no lado superior do eletrodo, mas, pôde-se observar, através de cálculos, que essa medição não indicava a temperatura real da amostra, mas sim valores ligeiramente superiores.

Como o calor foi aplicado na amostra somente pelo seu lado superior, a fim de se obter maior maleabilidade da folha inferior, para uma formação adequada das microbolhas, concluiu-se ser necessário elevar-se a temperatura também do eletrodo inferior. Tal inovação também seria necessária para se produzir uma perfeita aderência entre as duas folhas de Teflon FEP.

Esse protótipo inicial deu origem à elaboração de um projeto mais robusto, onde o calor é aplicado sobre as duas paredes do sensor piezelétrico. 


\section{4 - Segundo protótipo}

Tendo em vista os inúmeros problemas levantados no projeto anterior, tais como a falta de controle na temperatura aplicada no sistema, idealizou-se um novo protótipo, no qual, para uma maior eficiência, o aquecimento foi aplicado tanto no eletrodo superior quanto no inferior, com temperaturas controladas de forma independente. O cerne do controle térmico foi feito por um circuito elétrico de baixa potência e um termostato. Na figura 19, encontrase um diagrama esquemático do projeto elaborado.

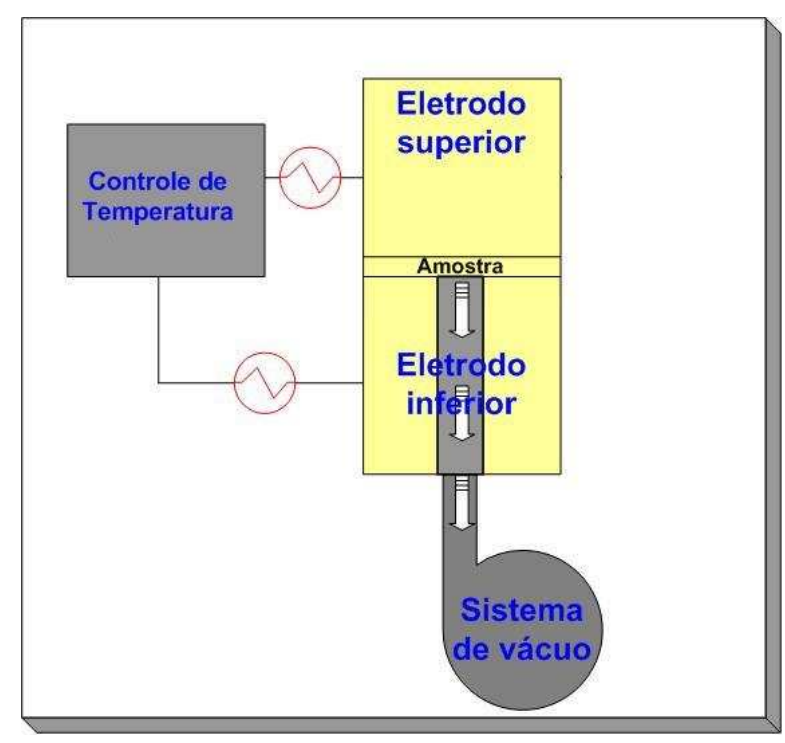

Figura 19 - Diagrama Esquemático do segundo protótipo, com detalhe para o sistema de vácuo e controle de temperatura independente para os eletrodos.

A base inferior foi reconstruída, mas manteve todos os princípios do sistema anterior, aprimorando a malha metálica que efetivamente melhor redistribui o vácuo e possibilita uma melhor fixação da folha de teflon sobre a grade metálica, como ilustra a figura 20. Construída em latão, contém micro furos que formam uma rede compacta. Sobre essa base furada foi projetado um canal, onde grades metálicas com diferentes malhas podem se acomodar. Com isso, podem-se obter diferentes tamanhos de microbolhas, apenas alterando-se a dimensão da malha. Como conseqüência direta, diferentes 
sensores piezelétricos podem ser produzidos, cada um com uma resposta diferente em freqüência.

Ao se aquecer a base inferior do dispositivo, a folha de teflon tende a se adequar sobre a malha da grade, devido principalmente ao sistema de vácuo. Isto denota várias vantagens sobre os sistemas anteriores:

A folha de teflon se ajusta perfeitamente à grade metálica;

$>$ O sistema de vácuo suga a folha de teflon com maior eficiência e com isso,

> Observa-se uma formação de microbolhas mais uniforme.

No lado superior, também presa a uma resistência elétrica, uma base de latão, incorporando um eletrodo circular, foi adicionada ao sistema, para produzir uma pressão adequada em temperatura controlada, sobre a folha superior da amostra sensorial.

A atuação conjunta das bases aquecidas convenientemente traduz um processo de aderência das folhas de teflon com maior perfeição. Controlandose convenientemente as temperaturas e o tempo de exposição, as duas folhas de teflon aderem somente nas partes comuns, deixando livre as demais formadas pelas microbolhas.

Atualmente, amostras têm sido desenvolvidas nesse sistema inovador, onde microbolhas uniformes são produzidas, tendo seu diâmetro variado conforme a malha metálica utilizada, diretamente proporcional ao vácuo aplicado no sistema.

Com isso, observou-se uma melhoria das respostas piezelétricas, oriundas do sensor. Um projeto desenvolvido paralelamente por Altafim R.A.C. tem confirmado o sucesso deste projeto.

A figura 20 revela o sistema edificado no laboratório. 


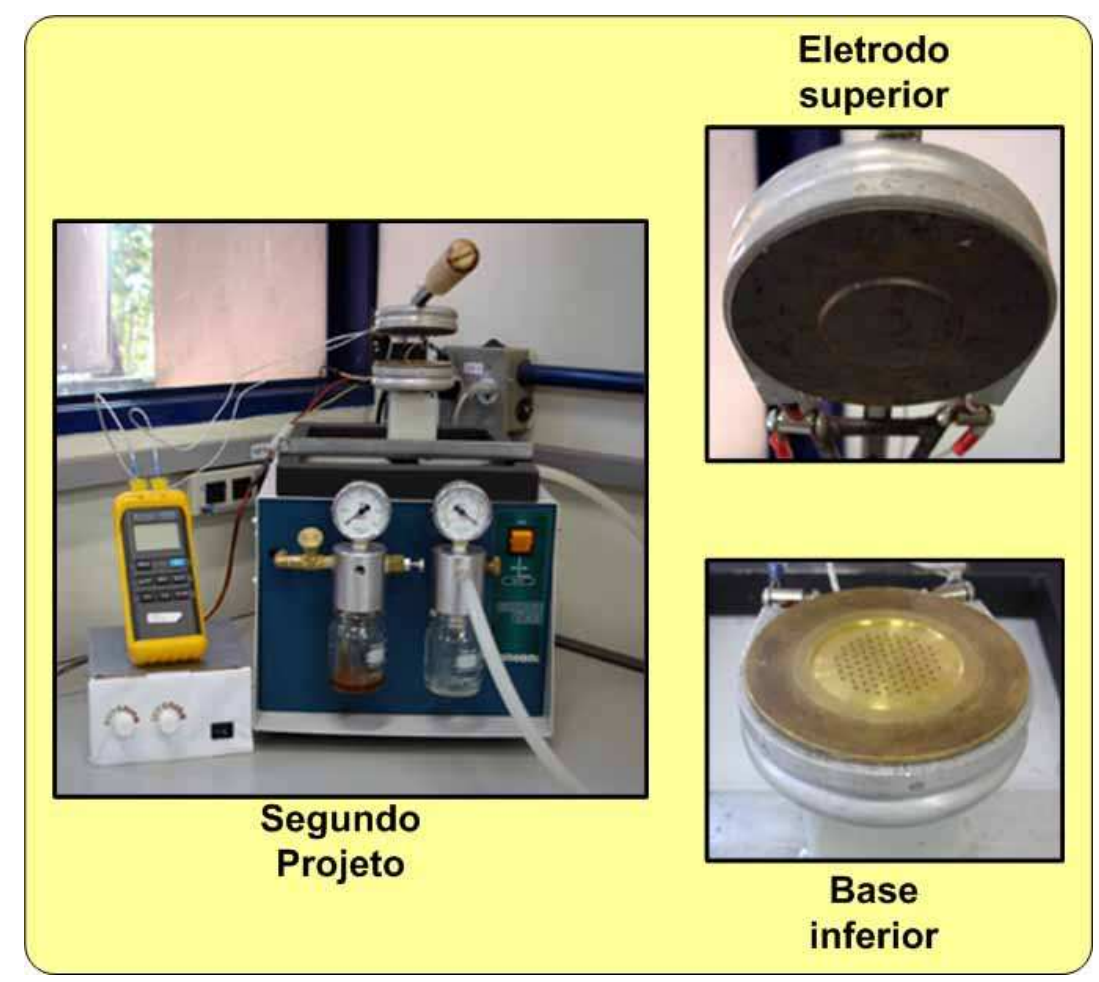

Figura 20 - Segundo projeto desenvolvido no Laboratório de Medidas e Padrões da EESC/USP.

Tendo em vista que este projeto possui um completo controle de temperatura independente para cada base, bem como um sistema de vácuo controlado, podem-se obter diversos tipos de sensores piezelétricos.

\section{5 - Desenvolvimento de um sistema para medição das características estáticas dos sensores piezelétricos.}

Todo material, antes de ser exposto no mercado, precisa ser caracterizado e testado exaustivamente, a fim de se garantirem as vantagens e limitações de uso do produto. Atualmente, as empresas têm sofrido a pressão dos indicadores de qualidade sobre seus produtos. Cada vez mais as metas têm sido afuniladas para garantir resultados cada vez melhores.

O sensor piezelétrico de Teflon FEP, antes de se apresentar como produto final e ser comercializado, tanto no mercado interno quanto no externo, 
necessita de uma caracterização do ponto de vista elétrico e mecânico, para que se possam conhecer seus limites de operação.

Para tanto, serão levantadas as curvas de resposta do sistema projetado e do sensor piezelétrico, na tentativa de se exibir sua faixa de linearidade, garantindo, assim, sua aplicação em diversas áreas, tais como sensor de presença ou de toque, balanças, transdutores de pressão, etc.

\subsection{1 - Fatores influentes na determinação da resposta do sensor}

O transdutor piezelétrico de Teflon FEP responde bem tanto a uma excitação mecânica quanto a uma elétrica. No primeiro caso, quando se aplica uma força conhecida sobre o sensor, o dispositivo responde com um sinal elétrico proporcional à excitação mecânica. Por dualidade, ao excitar o sensor com um sinal elétrico, ele responde com uma deformação mecânica.

Quando se tem uma força mecânica como entrada, o sinal elétrico exibido da ordem de milivolts depende de vários fatores, tais como:

> Número de camadas do transdutor versus força aplicada;

> Disposição e tamanho das bolhas de ar;

> Nível de tensão de carregamento da amostra;

> Intensidade da força mecânica aplicada (medida indireta);

> Intensidade do sinal elétrico aplicado (medida direta);

$>$ Umidade, temperatura e pressão envolvidas na etapa de fabricação do transdutor piezelétrico;

> Sistema de medição.

O sinal elétrico resultante é dependente diretamente do número de camadas do transdutor piezelétrico, respeitando-se o patamar estabelecido pelas condições de projeto e carregamento do dispositivo. A princípio, quanto maior o número de camadas, maior o coeficiente piezelétrico conseguido. 
Nos sensores anteriormente produzidos no Brasil, não se tinha um real controle das bolhas de ar dentro das amostras dos sensores de Teflon FEP. A disposição aleatória destes vacúolos gasosos produzia sinais de amplitudes variadas, que reduziam o sinal final. A homogeneidade desses vacúolos no processo de elaboração desta pesquisa contribuiu para a obtenção de um sinal mais característico, confiável, repetitivo e constante.

O nível de tensão de carregamento também influencia na quantidade de cargas armazenadas, ao passo que este é diretamente proporcional à quantidade de cargas armazenadas na superfície do teflon. Segundo Altafim (1998), este procedimento também apresenta limites, porque o carregamento das microbolhas está limitado a um fenômeno conhecido como "Back Discharge" (WHITEREAD, 1951). Esse fenômeno provoca um descarregamento elétrico natural das bolhas logo após terem sido submetidas a um carregamento elétrico excessivo. Ocorre uma reversão do campo elétrico interno que produz microdescargas.

Outro fator importante é a amplitude do sinal de entrada (força mecânica ou sinal elétrico) aplicada ao transdutor piezelétrico. A variação da amplitude na entrada é diretamente proporcional à amplitude do sinal resposta do transdutor, observados também seus limites de saturação.

O transdutor apresenta uma boa resposta em condições laboratoriais, isto é, de 20 a $60 \%$ e 20 a $27^{\circ} \mathrm{C}$ de umidade e temperatura, respectivamente. Ensaios posteriores serão feitos para testar o produto em condições extremas de uso, bem como sua atuação em grandes variações de pressão. Sabe-se de antemão que, quanto menor a umidade durante o processo de fabricação do sensor, maior será a possibilidade de retenção de carga pelo sensor, pois a umidade contribui negativamente para a ocorrência do breakdown no interior do vacúolo gasoso.

Por fim, esses transdutores projetados são, em síntese, geradores de tensão de baixíssima potência, e como tal, a medição de seus sinais deve ser feita por equipamento de alta impedância, com dezenas de megaOhms. 
Também seu emprego requer um casamento com dispositivos de alta impedância tipo transistores FET.

\subsection{2 - Resposta do sensor a um impulso mecânico}

A resposta ao impulso mecânico de um sensor é obtida aplicando-se um degrau de amplitude infinita e duração nula e medindo-se a respectiva resposta por um equipamento apropriado.

Para se medir a resposta ao impulso dos sensores desenvolvidos, foi construído um braço mecânico para a aplicação de força conhecida sobre a amostra e medindo-se um sinal elétrico gerado inicialmente por um osciloscópio.

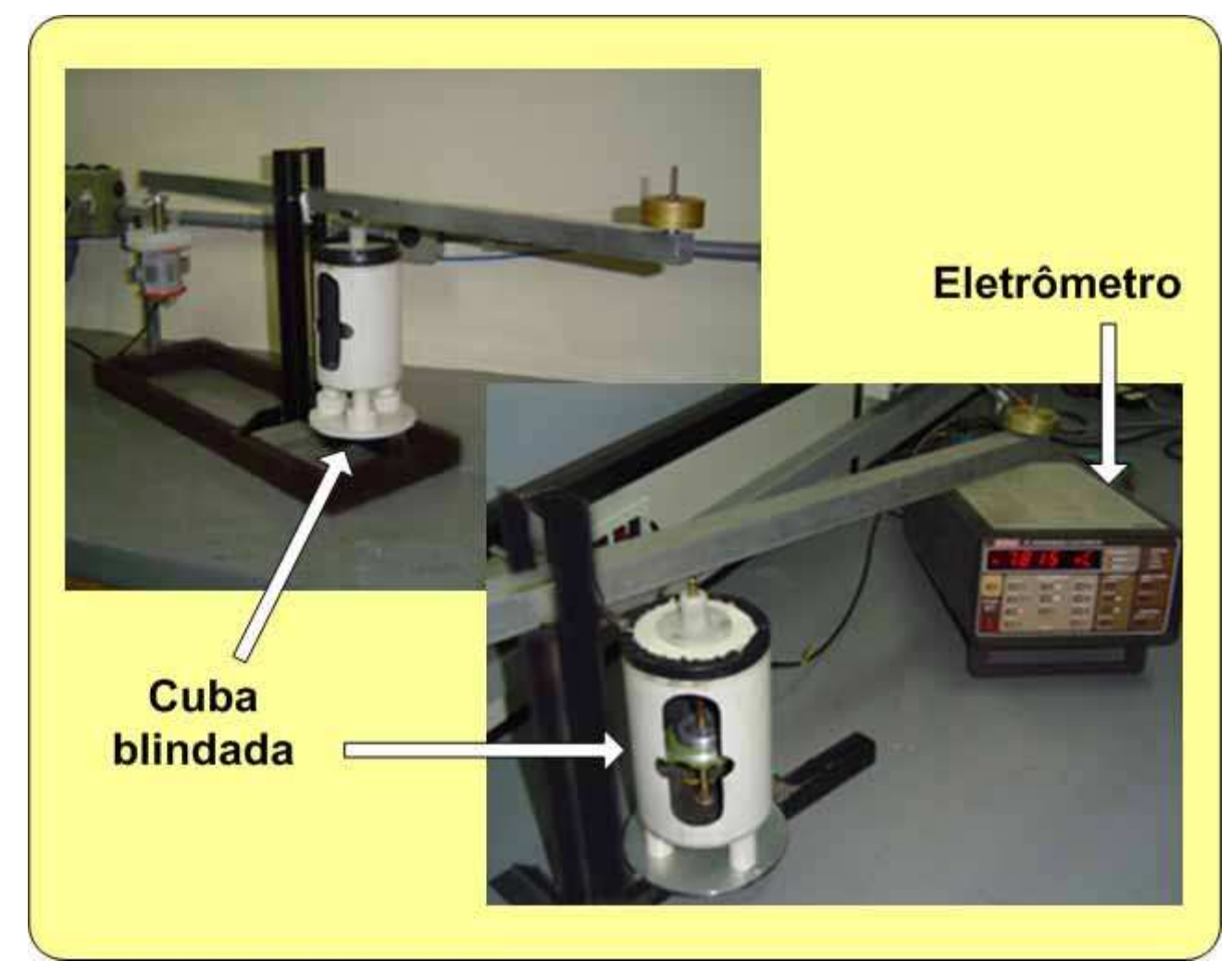

Figura 21 - Sistema mecânico para determinação da resposta ao impulso.

Nesse sistema, detalhado na figura 21, a amostra é inserida no interior de uma cuba blindada e aterrada para se evitarem ruídos externos. A carga, 
depositada na extremidade do braço, transfere para a amostra uma força cinco vezes maior, devido à razão de o braço ter sido projetado na proporção 5:1. O eletroímã tem o papel de aliviar a carga sobre a amostra, que apresenta um sinal de tensão da ordem de milivolts.

Tanto na aplicação quanto na retirada de carga, a amostra sofre uma deformação, um diferencial de deslocamento, liberando um sinal elétrico a um sistema de armazenamento de cargas, que, por sua vez, entrega o sinal a um sistema de aquisição de dados.

O sistema de aquisição de dados utilizado inicialmente era um osciloscópio digital Hewllet Packward modelo 5461B, cuja impedância de entrada é de $1 \mathrm{M} \Omega$. Entretanto, devido à baixa impedância de entrada do osciloscópio, o sinal observado era muito pequeno e distorcido. Na tentativa de evitar tal problema, substituiu-se o osciloscópio por um eletrômetro digital, obtendo-se assim os valores reais de resposta da amostra.

O sinal elétrico de resposta do eletrômetro apresentou um coeficiente piezelétrico de 10 a $15 \%$ maior do que o sinal observado no osciloscópio, confirmando assim o carregamento do sistema anterior, devido ao não casamento de impedância.

\section{6 - Resultados dos projetos}

Com os desenvolvimentos do trabalho exposto acima, vários tipos de amostras foram construídas, testadas e aprimoradas mediante os resultados apresentados. Assim como em um sistema realimentado, cada resposta insatisfatória foi utilizada como parâmetro de adaptação e de melhoria para o processo de fabricação dos transdutores piezelétricos.

Inicialmente, com o primeiro projeto implementado, vários termosensores com dupla camada de teflon foram fabricados. Estes sensores sofreram um aquecimento desigual em suas superfícies, pois somente 0 eletrodo superior era aquecido através de um maçarico comum. A base inferior permanecia à temperatura ambiente, sustentando a amostra sob um sistema 
de vácuo. Esse sistema tinha o papel de "sugar" a folha inferior de teflon para uma melhor formação das microbolhas.

Apesar da aderência obtida não ser de maneira adequada, a colagem superficial resultante permitiu que a amostra fosse submetida ao processo de metalização e posteriormente, testes mecânicos foram realizados para verificar a resposta piezelétrica do dispositivo.

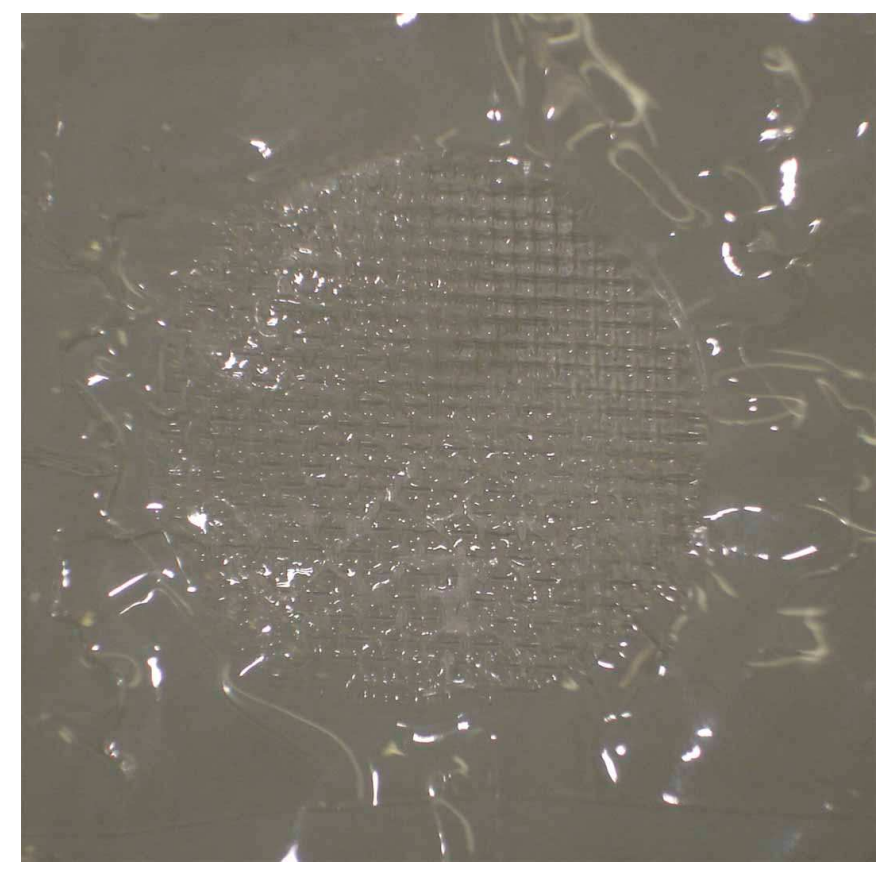

Figura 22 - Eletretos termo formados com várias deformidades.

Neste processo, foi difícil se obter um transdutor perfeito, pois devido à grande diferença de temperatura em que as folhas do filme polimérico eram submetidas, certas partes do filme apresentaram um derretimento excessivo, gerando buracos internos não uniformes.

Com o advento do segundo projeto, as amostras se portaram melhores e mais dinâmicas, apresentando uma resposta estática e dinâmica satisfatória. $O$ processo de fabricação se tornou mais refinado devido ao fino controle de temperatura implementado. As amostras sensoriais fabricadas neste novo processo apresentaram maior estabilidade mecânica e elétrica. 


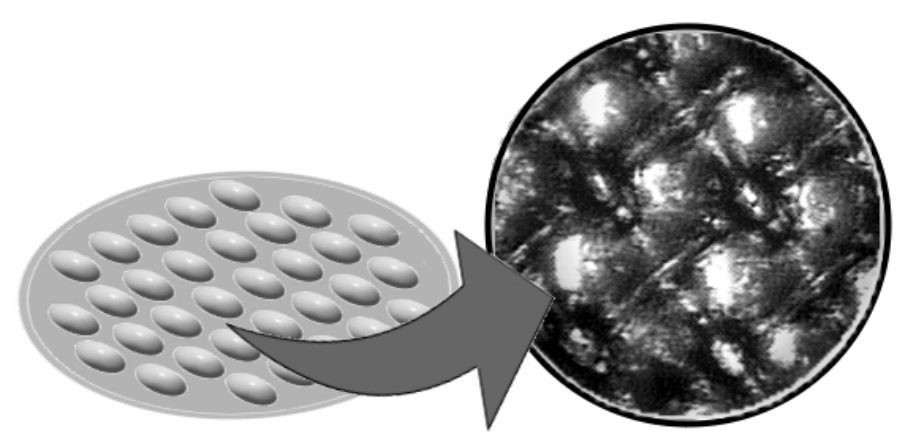

Figura 23 - Amostra sensorial com bolhas superficiais distribuídas uniformemente.

Observa-se a formação de microbolhas de ar uniformes em toda a superfície do transdutor piezelétrico.

No carregamento impulsivo, o processo de polarização que ocorre no interior das microbolhas é através de descargas elétricas no gás (ar), gerando cargas de polaridades opostas nas superfícies superior e inferior das bolhas.

Cada vacúolo gasoso, quando carregado por um impulso elétrico adequado, exibe uma atividade piezelétrica, resultando em altos níveis de coeficientes piezelétricos, como apresentados graficamente. 


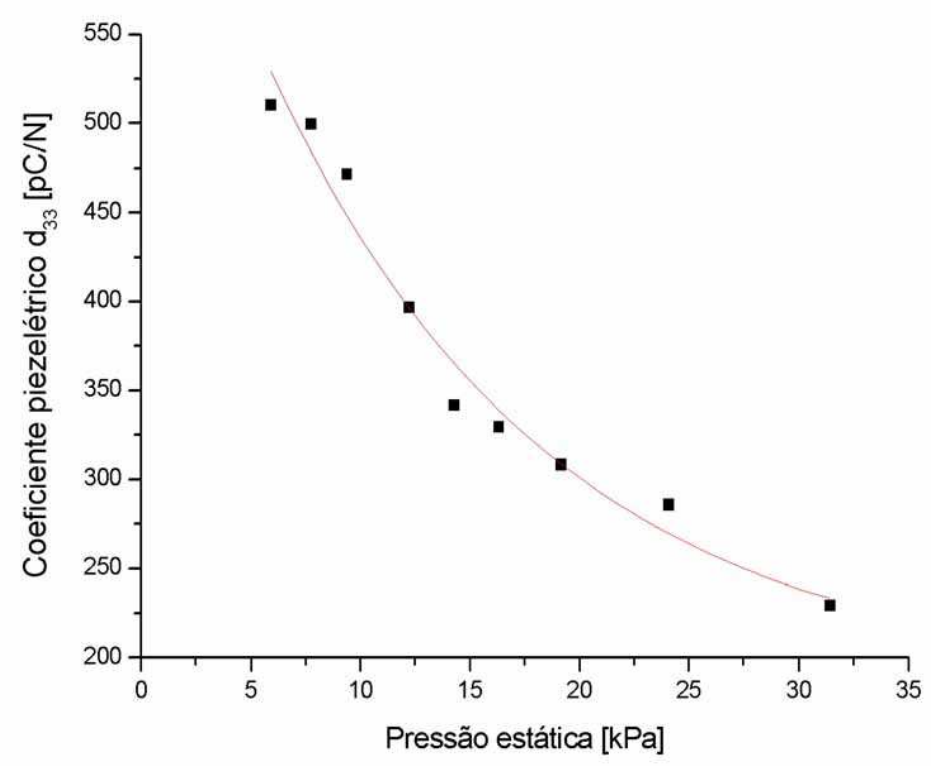

Figura 24 - Resposta piezelétrica do transdutor piezelétrico de Teflon FEP com bolhas superficiais distribuídas uniformemente.

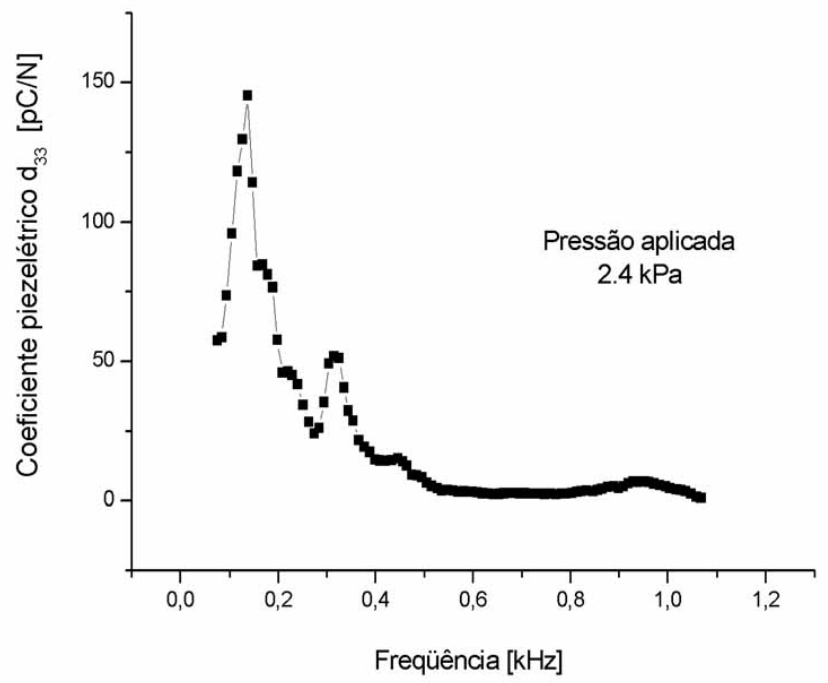

Figura 25 - Resposta piezelétrica do transdutor piezelétrico de Teflon FEP com bolhas superficiais distribuídas uniformemente. 
Nos gráficos, os termos sensores foram carregados com um pico de tensão negativa de $7,5 \mathrm{kV}$, pois conforme Altafim (1992) existe um valor limite para a tensão de pico de carregamento, onde não é mais possível obter separação de cargas dentro das microbolhas. Este patamar de carregamento é devido à ocorrência de descargas elétricas reversas dentro dos vacúolos, denominadas de back-discharges, que descarregam as microbolhas. 


\section{5 - CONCLUSÕES}

Os sensores termofomados elaborados com o filme polimérico de Teflon FEP exibiram grande atividade piezelétrica, com coeficientes superiores a 250 $\mathrm{pC} / \mathrm{N}$ quando carregados impulsivamente. Eles por apresentarem uma relação custo-benefício inferior aos sensores atuais abrem grandes perspectivas de comercialização. Somado a isto, a característica do Teflon FEP de reter cargas elétricas (principalmente cargas negativas) por longos períodos, ser um material dúctil e maleável, conferem-Ihe qualidades de poder ser aplicado a em diferentes situações, quer seja um sensor circular, retangular, ou alguma forma geométrica específica, de acordo com a necessidade de sua aplicação.

Obedecendo aos limites de temperatura e tensão de carregamento, é possível conseguir um sensor altamente eficiente que, em conjunto com um software de aquisição de dados, pode ser utilizado em balanças comerciais, sensor de vibração para a engenharia, transdutores de pressão eletroacústicos, etc. Observa-se que alguns desses trabalhos já estão em andamento.

Ressalta-se ainda o baixo custo de produção do sensor piezelétrico termoformado de Teflon FEP que possibilita uma produção em larga escala, visto que o investimento para tal projeto não é alto. Como o mercado atual utiliza sensores eletroacústicos nas mais diversas aplicações, uma aceitação por um produto de baixo custo é assegurada.

Quanto às qualidades do sensor com este processo, ele apresentou grande repetitividade, com pontos particulares de ressonância.

Contudo, pesquisas ainda necessitam ser desenvolvidas com vista à: 
$>$ de uma caracterização dinâmica, para que se verifiquei os limites em freqüência que este sensor responde;

$>$ de estudos em diferentes gases no interior da amostra, para que se verifique alteração no coeficiente piezelétrico;

$>$ de uma verificação do coeficiente piezelétrico de maneira indireta, talvez por injeção de um sinal elétrico na entrada, para que se confirme o nível piezelétrico encontrado;

$>$ de estudos com diferentes materiais utilizados como eletrodos, a fim de substituir-se o ouro empregado e diminuir o custo do produto final;

$>$ de utilizar filmes poliméricos de teflon com diferentes espessuras.

Neste contexto, este novo sensor deixa aberto um amplo campo para o desenvolvimento de novas pesquisas de produtos em diferentes áreas tecnológicas, como por exemplo, a bioengenharia.

Como fruto deste trabalho, dois artigos foram submetidos ao IEEE:

Altafim, R. A. C.; Basso, H. C.; Altafim, R. A. P.; Lima, L.; Aquino, C. V.; Neto, L. G.; Gerhard-Multhaupt R. (2006). Piezoelectrets from thermo-formed bubble structures of fluoropolymer-electret films. IEEE Transaction on Dielectrics and Electrical Insularion.

Altafim, R. A. C.; Basso, H. C.; Neto L. G.; Lima, L.; Altafim, R. A. P.; Aquino C. V. (2005). Piezoelectricity in Multi-Air Voids Electrets. IEEE Conference on Electrical Insulation and Dielectric Phenomena, Tennesee, p.16-19. out. 
Juntamente com Cláudio V. de Aquino e Heitor C. Basso, pesquisas paralelas sobre o equacionamento teórico e a caracterização dos processos dinâmicos de medição dos termos sensores, respectivamente, este trabalho se dá como uma inovação tecnológica, visto que os níveis de coeficientes piezelétricos obtidos são comparáveis aos publicados por outros pesquisadores de renome. 


\section{6 - REFERÊNCIAS BIBLIOGRÁFICAS}

ALTAFIM, R.A.C. et al. (2006). Piezoelectrets from thermo-formed bubble structures of fluoropolymer-electret films. IEEE Transaction on Dielectrics and Electrical Insularion.

. (2005). Piezoelectricity in Multi-Air Voids Electrets. IEEE Conference on Electrical Insulation and Dielectric Phenomena, Tennesee, p.16-19. out.

. (2003). Piezoeletricity of multi-layers space-charge electrets from Teflon FEP film with homogeneous voids distributed on its surface. IEEE Conference on Electrical Insulation and Dielectric Phenomena, Albuquerque, p.225-228, out.

ALTAFIM, R.A.C.; FERREIRA, G.F.L.; GIACOMETTI, J.A. (1998). Selfcontrolled Pre-Breakdown Discharges in Planar Symmetry. IEEE Transactions on Dielectrics and Electrical Insulation, v.5, n.1, fev.

ALTAFIM, R.A.C.; GIACOMETTI, J.A.; JANISZEWSKI, J.M. (1992). A Novel Method for Electret Production using Impulse Voltages. IEEE Transactions on Electrical Insulation, v.27, n.4, ago. 
ALTAFIM, R.A.C. (1990). Eletreto: Novo Sensor de Tensões e Correntes Impulsivas. 192p. Tese (Doutorado) - Escola Politécnica, Universidade de São Paulo, São Paulo, 1990.

BALlato, A. (1996). Piezoelectricity: History and New Thrusts. IEEE Ultrasonics Symposium, v.1, p.575-583, nov.

. (1995). Piezoelectricity: Old Effect, New Thrusts. IEEE Transactions on Ultrasonics, Ferroelectrics, and Frequency Control, v.42, n.5, p.916-926, set.

BROW, C.S. et al. (1962). Piezoelectric Materials: A Review of Progress. Ire Transactions on Component Parts, p.193-211, dez.

DICTIONARY OF TECHNICAL TERMS FOR AEROSPACE USE (2004). National Aeronautics and Space Administration (NASA). Disponível em <http://roland.lerc.nasa.gov/ dglover/dictionary/content.html>. Acesso em: 15 maio.

DUPONT. Teflon FEP and Tefzel Films. (2005). Disponível em: <http://www.dupont.com/teflon/films/H-55008-2.html>. Acesso em: 28 mar.

FUKADA, E. (2000). History and Recent Progress in Piezoelectric Polymers. IEEE Transactions on Ultrasonics, Ferroelectrics, and Frequency Control. v.47, n.6, p.1277-1290, nov.

GERHARD-MULTHAUPT, R. et al. (2002a). Electrode poling of cellular polypropylene films with short high-voltage pulses. IEEE Conference on Electrical Insulation and Dielectric Phenomena, p.299-302, out. 
. (2002b). Less can be More: Holes in Polymer lead to a New Paradigm

of Piezoelectric Materials for Electret Transducers. IEEE Transactions on Dielectrics and Electrical Insulation, New York, v.9, n.5, p.850-859.

. (1999). Electrets. In: Topics in Applied Physics, v33. 3.ed., v.2, Morgan Hill, Laplacian Press.

HILCZER, B.; MALECKI, J. (1986). Electrets. Warszawa, Polish Scientific Publishers.

HILLENBRAND, J.; SESSLER, G. M. (2004). Quasistatic and Dynamic Piezoelectric Coefficients of Polymer Foams and Polymer Film System. IEEE Transactions on Dielectrics and Electrical Insulation, v.11, n.1, fev. ; __ (2000). Piezoelectricity in Cellular Electrec Films. IEEE Transactions on Dielectrics and Electrical Insulation, v.7, n.4, ago.

KESTELMAN, V.N.; PINCHUK, L.S.; GOLDADE V.A. (2000). Electrets in Engineering: Fundamentals and Applications. Boston: Kluwer Academic Publishers.

RODRIGUES, E.M.F. (2003). Novos sensores piezoelétricos com eletretos de Teflon FEP. 54p. Dissertação (Mestrado) - Escola de Engenharia de São Carlos, Universidade de São Paulo, São Carlos, 2003.

SESSLER, G.M. (2001). Electrets: recent developments. Journal of Electrostatics, v.51-52, p.137-145. 
. (1998). Electrets. In: Topics in Applied Physics, v33. 3.ed., v.1, Morgan

Hill, Laplacian Press.

WANG, T.T.; HERBERT, J.M.; GLASS, A.M. (1988). The applications of ferroelectric polymers. Editora Blackie and Son Ltd (Glasgow and London)

WHITEHEAD, S. (1951). Dielectric Breakdown of Solids. In: Monographs on the Physics and Chemistry of Materials, v.8. Oxford, Clarendon Press. 
ANEXO A - CARACTERÍSTICAS DO TEFLON FEP 


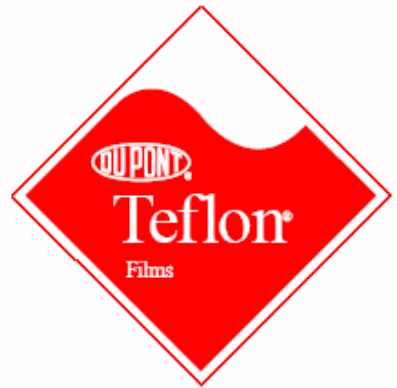

High Performance Films

\section{DuPont FEP}

\section{fluorocarbon film}

\section{Description}

DuPont FEP film is a transparent, thermoplastic film that can be heat sealed, thermoformed, vacuum formed, heat bonded, welded, metalized, laminated-combined with dozens of other materials, and can also be used as an excellent hot-melt adhesive

This wide variety of fabrication possibilities combines with the following important properties to offer a unique balance of capabilities not available in any other plastic film.

\section{Chemical Compatibility}

- Teflon ${ }^{\circledR}$ is the most inert of all plastics.

- Complies with USFDA legislations for safe use with food

- DuPont FEP film is chemically inert and solventresistant to virtually all chemicals, except molten alkali metals, gaseous fluorine, and certain complex halogenated compounds such as chlorine trifluoride at elevated temperatures and pressures.

- Low permeability to liquids, gases, moisture, and organic vapors

\section{Electrical Reliability}

- Superior reliability and retention of properties over large areas of film

- High dielectric strength, over $6500 \mathrm{~V} / \mathrm{mil}$ for

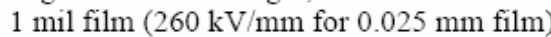

- No electrical tracking, non-wettable, and noncharring

- Very low power factor and dielectric constant, only slight change over wide ranges of temperature and frequency

Teflon ${ }^{*}$ is a registered trademark of DuPont.
Properties Bulletin

\section{Wide Thermal Range}

- Continuous service temperature -240 to $205^{\circ} \mathrm{C}$ $\left(-400\right.$ to $\left.400^{\circ} \mathrm{F}\right)$

- Melting range 250 to $280^{\circ} \mathrm{C}\left(500\right.$ to $\left.540^{\circ} \mathrm{F}\right)$

- Heat sealable

\section{Mechanical Toughness}

- Superior antistick and low frictional properties

- High resistance to impact and tearing

- Useful physical properties at cryogenic temperatures

\section{Long Time Weatherability*}

- Inert to outdoor exposure; no measurable change after 20 years in Florida

- High transmittance of ultraviolet and all but far infrared

\section{Reliability}

- DuPont FEP film contains no plasticizers or other foreign materials

- Conventional equipment and techniques can be used for processing: basic composition and properties will not be influenced

- Rigid quality control by DuPont ensures uniform gauge, void-free film

The convenience of Teflon ${ }^{\mathbb{E}}$ in easy-to-use film facilitates the design and fabrication of this lowfriction thermoplastic for all sorts of highperformance jobs. It is transparent and can be heat sealed, thermoformed, welded, and heat bonded.

*Type $\mathrm{C}$ film not recommended for outdoor use 
Superior antistick properties make it an ideal release film for many applications. A cementable type with an invisible surface treatment is available for bonding to none or both sides with adhesives.
This versatility is augmented by the superior properties of a true melt-processible fluorocarbon and by the wide choice of product dimensions available from DuPont

Table 1

Types and Gauges of DuPont FEP Fluorocarbon Film

\begin{tabular}{|c|c|c|c|c|c|c|c|c|c|c|c|c|c|c|}
\hline Gauge & 50 & 100 & 200 & 300 & 500 & 750 & 1000 & 1500 & 2000 & 3000 & 6000 & 9000 & 12500 & 19000 \\
\hline Thickness, mil & 0.5 & 1 & 2 & 3 & 5 & 7.5 & 10 & 15 & 20 & 30 & 60 & 90 & 125 & 190 \\
\hline Thickness, $\mu \mathrm{m}$ & 12.5 & 25 & 50 & 75 & 125 & 190 & 250 & 375 & 500 & 750 & 1500 & 2300 & 3125 & 4750 \\
\hline Approximate area factor, $\mathrm{ft}^{2} / \mathrm{lb}$ & 180 & 90 & 45 & 30 & 18 & 12 & 9 & 6.0 & 4.5 & 3 & 1.5 & 1 & 0.72 & 0.47 \\
\hline Approximate area factor, $\mathrm{m}^{2} / \mathrm{kg}$ & 36 & 18 & 9 & 6 & 4 & 2.5 & 2 & 1.2 & 1 & 0.6 & 0.3 & 0.2 & 0.14 & 0.09 \\
\hline \multicolumn{15}{|l|}{ Availability } \\
\hline Type A-FEP, general-purpose & $x$ & $\mathrm{X}$ & $\mathrm{x}$ & $\mathrm{x}$ & $\mathrm{x}$ & $\mathrm{x}$ & $x$ & - & $\mathrm{X}$ & - & - & - & - & - \\
\hline $\begin{array}{l}\text { Type } \mathbf{C} \text { _FEP, one side } \\
\text { cementable }\end{array}$ & $\mathrm{X}$ & $\mathrm{X}$ & $\mathrm{X}$ & $\mathrm{X}$ & $\mathrm{x}$ & - & - & - & - & - & - & - & - & - \\
\hline $\begin{array}{l}\text { Type C-20_FEP, both sides } \\
\text { cementable }\end{array}$ & $\mathrm{X}$ & $\mathrm{X}$ & $\mathrm{x}$ & - & $\mathrm{x}$ & - & - & - & - & - & - & - & - & - \\
\hline $\begin{array}{l}\text { Type L-FEP, high stress crack } \\
\text { resistance in extreme } \\
\text { environments }\end{array}$ & - & - & - & - & $\mathrm{x}$ & - & $\mathrm{X}$ & $\mathrm{X}$ & $\mathrm{x}$ & $\mathrm{x}$ & $x$ & $x$ & $x$ & $X$ \\
\hline
\end{tabular}

Note: Each roll of DuPont film is clearly identified as to resin type, film thickness, and film type.

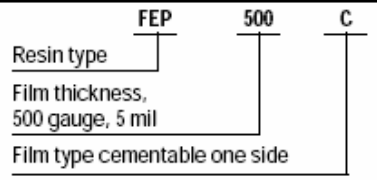


Property Values of DuPont FEP Fluorocarbon Film

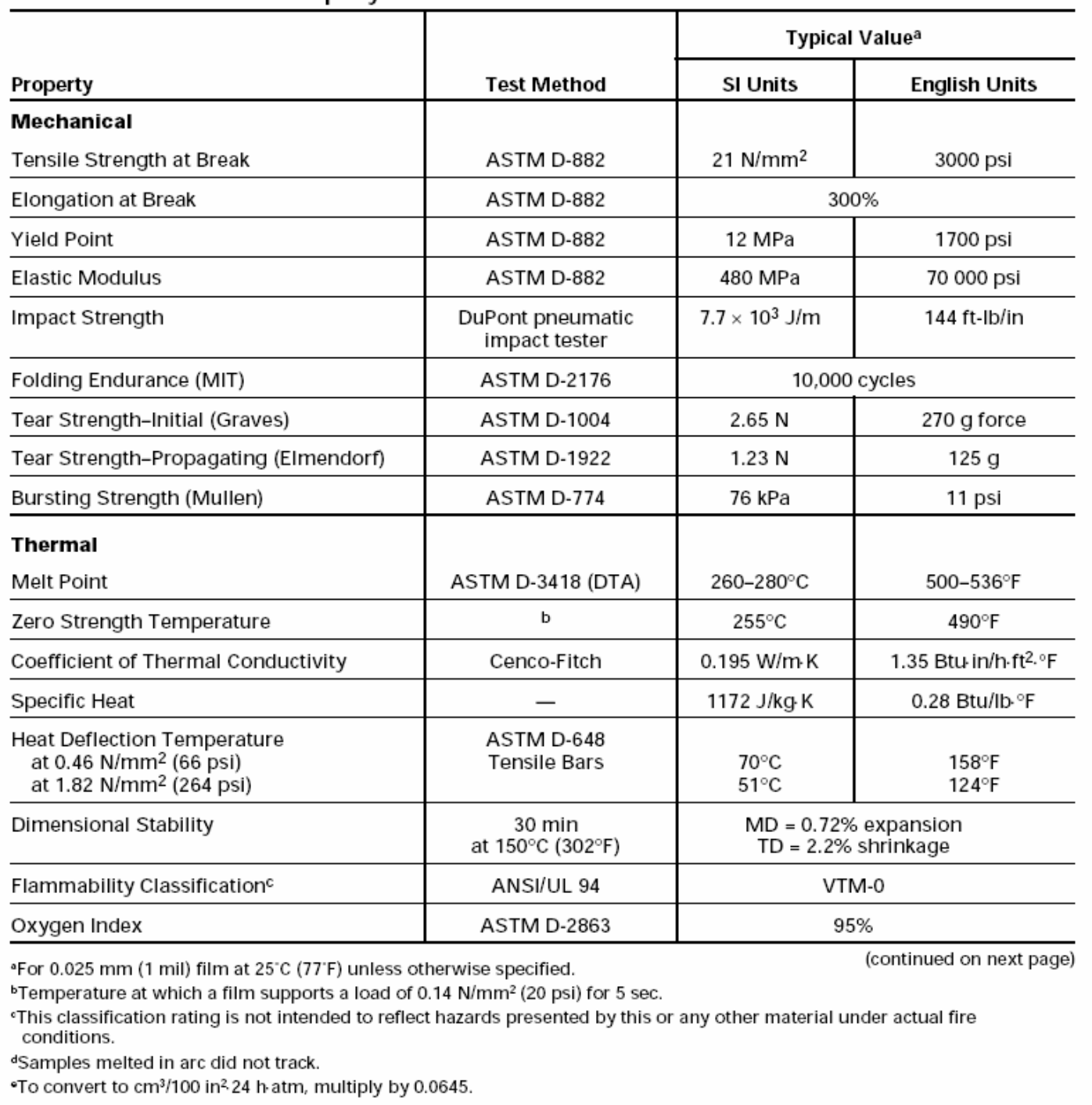


Property Values of DuPont FEP Fluorocarbon Film (continued)

\begin{tabular}{|c|c|c|c|}
\hline \multirow[b]{2}{*}{ Property } & \multirow[b]{2}{*}{ Test Method } & \multicolumn{2}{|c|}{ Typical Value ${ }^{a}$} \\
\hline & & SI Units & English Units \\
\hline \multicolumn{4}{|l|}{ Electrical } \\
\hline $\begin{array}{l}\text { Dielectric Strength, short-time } \\
\text { in air at } 23^{\circ} \mathrm{C}\left(73^{\circ} \mathrm{F}\right) \text {, } \\
6.35 \mathrm{~mm}(1 / 4 \mathrm{in}) \text { diameter electrode, } \\
0.79 \mathrm{~mm}(1 / 32 \mathrm{in}) \text { radius } \\
60 \mathrm{~Hz}, 500 \mathrm{~V} / \mathrm{s} \text { rate of rise: } \\
0.025 \mathrm{~mm}(1 \mathrm{mil}) \text { film } \\
5 \mathrm{~mm}(20 \mathrm{mil}) \text { film }\end{array}$ & $\begin{array}{l}\text { ASTM D-149 } \\
\text { Method A }\end{array}$ & $\begin{array}{l}260 \mathrm{kV} / \mathrm{mm} \\
70 \mathrm{kV} / \mathrm{mm}\end{array}$ & $\begin{array}{l}6500 \mathrm{~V} / \mathrm{mil} \\
1800 \mathrm{~V} / \mathrm{mil}\end{array}$ \\
\hline $\begin{array}{l}\text { Dielectric Constant, } \\
25^{\circ} \mathrm{C}\left(77^{\circ} \mathrm{F}\right), 100 \mathrm{~Hz} \text { to } 1 \mathrm{MHz} \\
\quad-40 \text { to } 225^{\circ} \mathrm{C}\left(-40 \text { to } 437^{\circ} \mathrm{F}\right), 1000 \mathrm{~Hz}\end{array}$ & ASTM D-150 & \multicolumn{2}{|c|}{$\begin{array}{c}2.0 \\
2.02-1.93 \\
\end{array}$} \\
\hline $\begin{array}{l}\text { Dissipation Factor, } \\
25^{\circ} \mathrm{C}\left(77^{\circ} \mathrm{F}\right), 100 \mathrm{~Hz} \text { to } 1 \mathrm{MHz} \\
-40 \text { to } 225^{\circ} \mathrm{C}\left(-40 \text { to } 437^{\circ} \mathrm{F}\right), 1000 \mathrm{~Hz} \\
-40 \text { to } 240^{\circ} \mathrm{C}\left(-40 \text { to } 464^{\circ} \mathrm{F}\right), 1 \mathrm{MHz} \\
\end{array}$ & ASTM D-150 & \multicolumn{2}{|c|}{$\begin{array}{l}0.0002-0.0007 \\
0.0002 \\
0.0005\end{array}$} \\
\hline $\begin{array}{l}\text { Volume Resistivity, } \\
-40 \text { to } 240^{\circ} \mathrm{C}\left(-40 \text { to } 464^{\circ} \mathrm{F}\right)\end{array}$ & ASTM D-257 & \multicolumn{2}{|c|}{$>1 \times 10^{18} \mu \mathrm{m} \cdot \mathrm{cm}$} \\
\hline $\begin{array}{l}\text { Surface Resistivity, } \\
-40 \text { to } 240^{\circ} \mathrm{C}\left(-40 \text { to } 464^{\circ} \mathrm{C}\right)\end{array}$ & ASTM D-257 & \multicolumn{2}{|c|}{$>1 \times 10^{16} \Omega / \mathrm{sq}$} \\
\hline Surface Arc Resistance & ASTM D-495 & \multicolumn{2}{|c|}{$>165 \mathrm{sec}^{\mathrm{d}}$} \\
\hline $\begin{array}{l}\text { Insulation Resistance } \\
\text { at } 100^{\circ} \mathrm{C}\left(212^{\circ} \mathrm{F}\right) \\
\text { at } 150^{\circ} \mathrm{C}\left(302^{\circ} \mathrm{F}\right) \\
\text { at } 200^{\circ} \mathrm{C}\left(392^{\circ} \mathrm{F}\right)\end{array}$ & $\begin{array}{l}\text { Based upon } 0.2 \mathrm{MF} \\
\text { wound capacitor } \\
\text { sections, using single } \\
\text { layer, Teflon } 50 \mathrm{~A} \text { Film }\end{array}$ & \multicolumn{2}{|c|}{$\begin{array}{r}\text { 350,000 Mohm } \mu \mathrm{F} \\
250,000 \mathrm{Mohm} \cdot \mu \mathrm{F} \\
65,000 \mathrm{Mohm} \cdot \mu \mathrm{F}\end{array}$} \\
\hline \multicolumn{4}{|c|}{$\begin{array}{l}{ }^{\circ} \text { For } 0.025 \mathrm{~mm} \text { (1 mil) film at } 25^{\circ} \mathrm{C}\left(77^{\circ} \mathrm{F}\right) \text { unless otherwise specified. } \\
{ }^{\mathrm{b}} \text { Temperature at which a film supports a load of } 0.14 \mathrm{~N} / \mathrm{mm}^{2}(20 \mathrm{psi}) \text { for } 5 \mathrm{sec} . \\
\text { 'This classification rating is not intended to reflect hazards presented by this or any other material under actual fire } \\
\text { conditions. }\end{array}$} \\
\hline
\end{tabular}


Property Values of DuPont FEP Fluorocarbon Film (continued)

\begin{tabular}{|c|c|c|c|}
\hline \multirow[b]{2}{*}{ Property } & \multirow[b]{2}{*}{ Test Method } & \multicolumn{2}{|c|}{ Typical Value ${ }^{a}$} \\
\hline & & SI Units & English Units \\
\hline \multicolumn{4}{|l|}{ Chemical } \\
\hline Moisture Absorption & - & \multicolumn{2}{|c|}{$<0.01 \%$} \\
\hline Weatherability & $\begin{array}{l}\text { Continuous exposure } \\
\text { in Florida }\end{array}$ & \multicolumn{2}{|c|}{ No adverse effects after $20 \mathrm{yr}$} \\
\hline \multirow{2}{*}{$\begin{array}{l}\text { Permeability, Gas: } \\
\text { Carbon Dioxide } \\
\text { Hydrogen } \\
\text { Nitrogen } \\
\text { Oxygen }\end{array}$} & \multirow[t]{2}{*}{ ASTM D-1434 } & \multicolumn{2}{|c|}{$\mathrm{cm}^{3} / \mathrm{m}^{2} .24 \mathrm{~h}$-atme } \\
\hline & & \multicolumn{2}{|c|}{$\begin{array}{r}25.9 \times 10^{3} \\
34.1 \times 10^{3} \\
5.0 \times 10^{3} \\
11.6 \times 10^{3}\end{array}$} \\
\hline Permeability, Vapors: & ASTM E-96 & $\mathrm{g} / \mathrm{m}^{2} \cdot \mathrm{d}$ & $g / 100 \mathrm{in}^{2} 24 \mathrm{~h}$ \\
\hline $\begin{array}{l}\text { Acetic Acid } \\
\text { Acetone } \\
\text { Benzene } \\
\text { Carbon Tetrachloride } \\
\text { Ethyl Alcohol } \\
\text { Hexane } \\
\text { Water }\end{array}$ & & $\begin{array}{r}6.3 \\
14.7 \\
9.9 \\
4.8 \\
10.7 \\
8.7 \\
7.0\end{array}$ & $\begin{array}{l}0.41 \\
0.95 \\
0.64 \\
0.31 \\
0.69 \\
0.56 \\
0.40\end{array}$ \\
\hline
\end{tabular}

Teflon $^{\oplus}$ is chemically inert and solvent-resistant to virtually all chemicals except molten alkali metals, gaseous fluorine, and certain complex halogenated compounds such as chlorine trifluoride at elevated temperatures and pressures.

\begin{tabular}{l|c|c|c}
\hline $\begin{array}{l}\text { Miscellaneous } \\
\text { Density }\end{array}$ & ASTM D-1505 & $2150 \mathrm{~kg} / \mathrm{m}^{3}$ & $134 \mathrm{lb} / \mathrm{ft}^{3}$ \\
\hline $\begin{array}{l}\text { Coefficient of Friction } \\
\text { Kinetic (Film-to-Steel) }\end{array}$ & ASTM D-1894 & $0.1-0.3$ \\
\hline $\begin{array}{l}\text { Refractive Index } \\
\text { Solar Transmission }\end{array}$ & ASTM D-542 & $1.341-1.347$ \\
\hline
\end{tabular}

${ }^{\circ}$ For $0.025 \mathrm{~mm}$ ( $\left.1 \mathrm{mil}\right)$ film at $25^{\circ} \mathrm{C}\left(77^{\circ} \mathrm{F}\right)$ unless otherwise specified.

bTemperature at which a film supports a load of $0.14 \mathrm{~N} / \mathrm{mm}^{2}(20 \mathrm{psi})$ for $5 \mathrm{sec}$.

'This classification rating is not intended to reflect hazards presented by this or any other material under actual fire conditions.

¿Samples melted in arc did not track.

-To convert to $\mathrm{cm}^{3} / 100 \mathrm{in}^{2} \cdot 24 \mathrm{~h}$-atm, multiply by 0.0645 . 